\title{
Focus Group Study to Explore Critical Factors for Managing Stress of Construction Workers
}

DOI:

10.1061/(ASCE)CO.1943-7862.0001477

\section{Document Version}

Accepted author manuscript

Link to publication record in Manchester Research Explorer

\section{Citation for published version (APA):}

Liang, Q., Leung, M. Y., \& Cooper, C. L. (2018). Focus Group Study to Explore Critical Factors for Managing Stress of Construction Workers. Journal of Construction Engineering and Management, 144(5), [04018023]. https://doi.org/10.1061/(ASCE)CO.1943-7862.0001477

\section{Published in:}

Journal of Construction Engineering and Management

\section{Citing this paper}

Please note that where the full-text provided on Manchester Research Explorer is the Author Accepted Manuscript or Proof version this may differ from the final Published version. If citing, it is advised that you check and use the publisher's definitive version.

\section{General rights}

Copyright and moral rights for the publications made accessible in the Research Explorer are retained by the authors and/or other copyright owners and it is a condition of accessing publications that users recognise and abide by the legal requirements associated with these rights.

\section{Takedown policy}

If you believe that this document breaches copyright please refer to the University of Manchester's Takedown Procedures [http://man.ac.uk/04Y6Bo] or contact uml.scholarlycommunications@manchester.ac.uk providing relevant details, so we can investigate your claim.

\section{OPEN ACCESS}




\section{Journal of Construction Engineering and Management A FOCUS GROUP STUDY TO EXPLORE CRITICAL FACTORS FOR MANAGING STRESS OF THE CONSTRUCTION WORKERS \\ --Manuscript Draft--}

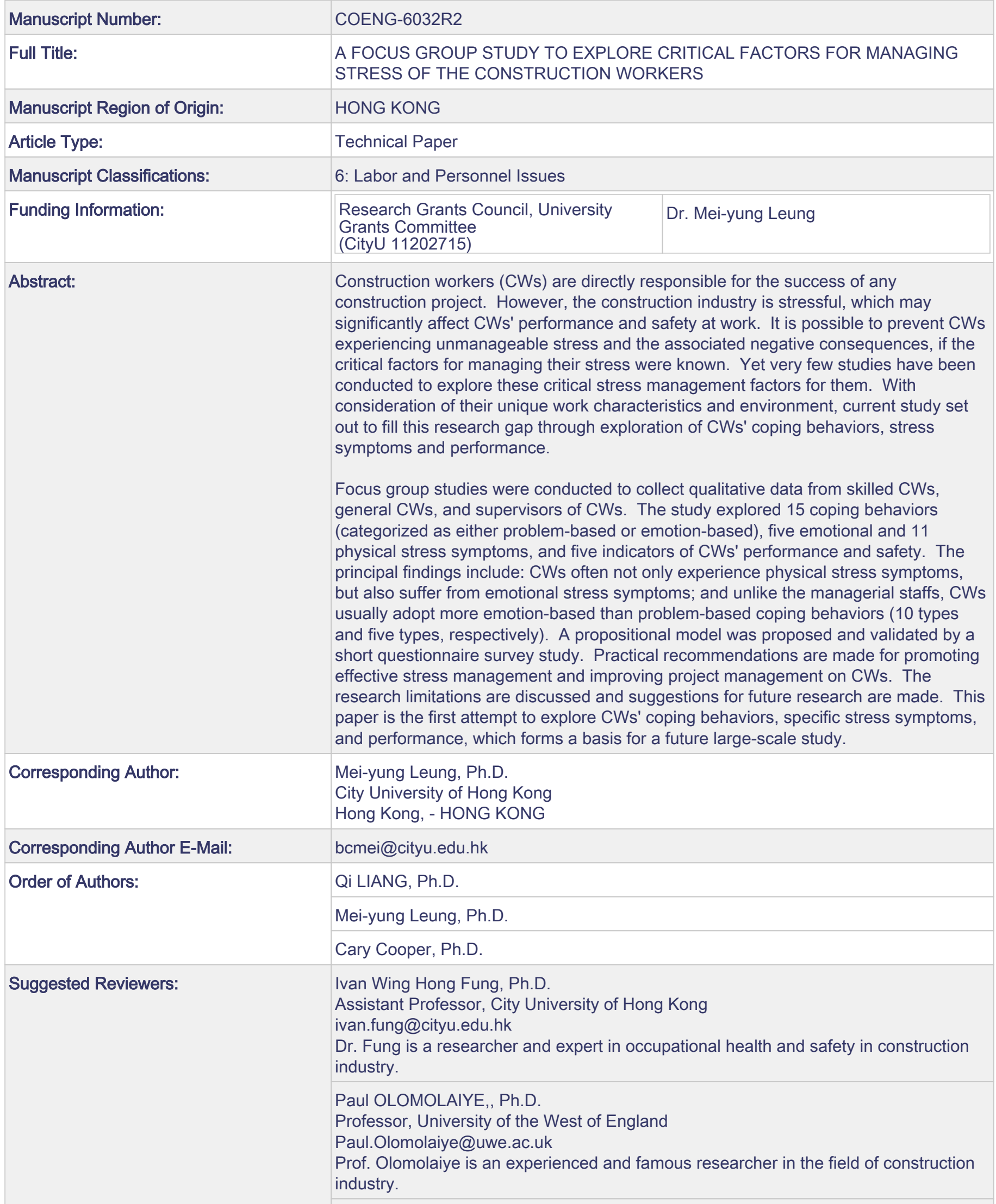




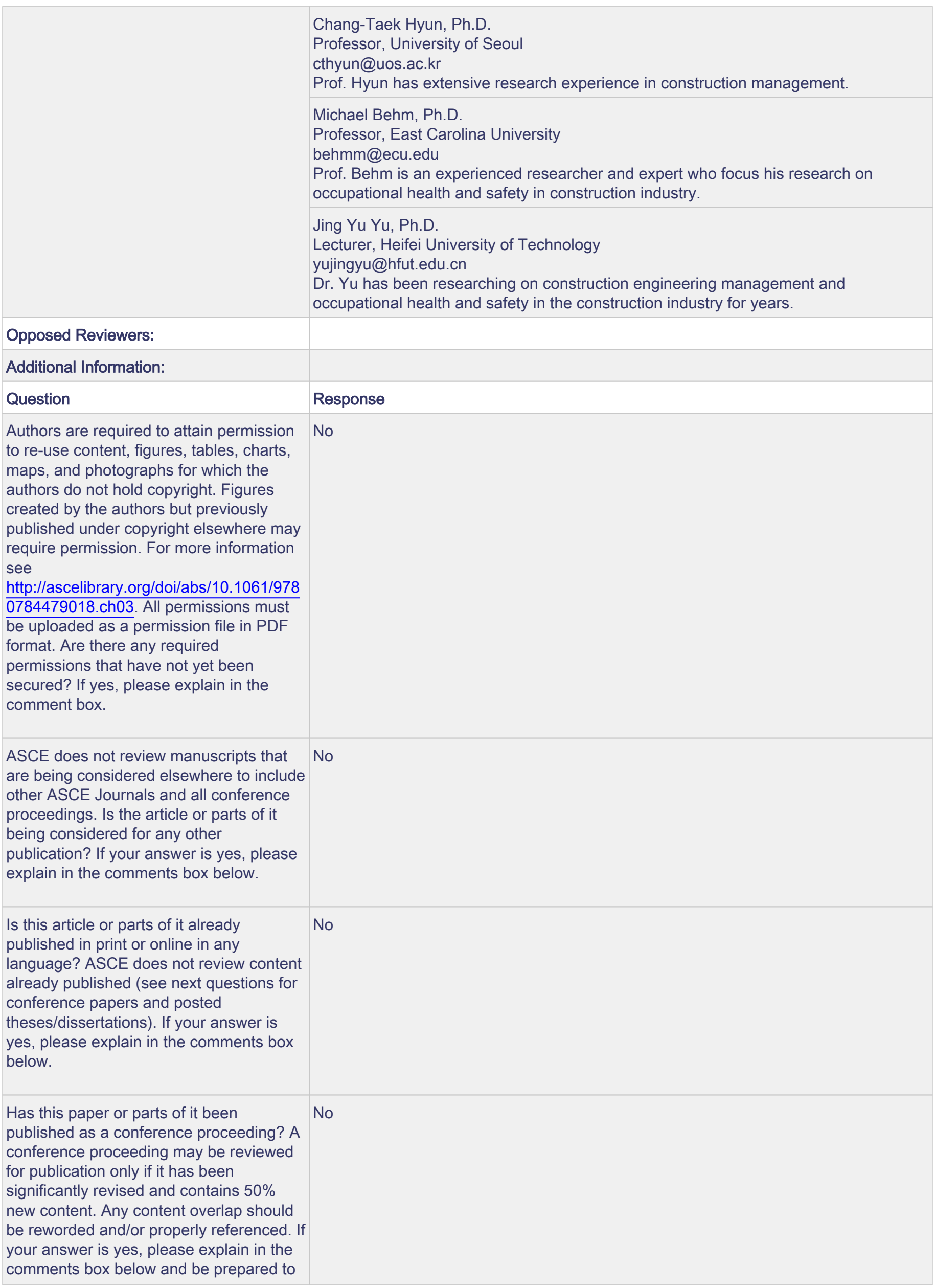


provide the conference paper.

ASCE allows submissions of papers that

are based on theses and dissertations so long as the paper has been modified to fit the journal page limits, format, and tailored for the audience. ASCE will consider such papers even if the thesis or dissertation has been posted online provided that the degree-granting institution requires that the thesis or dissertation be posted.

Is this paper a derivative of a thesis or dissertation posted or about to be posted on the Internet? If yes, please provide the URL or DOI permalink in the comment box below.

Each submission to ASCE must stand on

its own and represent significant new information, which may include disproving the work of others. While it is acceptable to build upon one's own work or replicate other's work, it is not appropriate to fragment the research to maximize the number of manuscripts or to submit papers that represent very small incremental changes. ASCE may use tools such as CrossCheck, Duplicate Submission Checks, and Google Scholar to verify that submissions are novel. Does the manuscript constitute incremental work (i.e. restating raw data, models, or conclusions from a previously published study)?

Authors are expected to present their papers within the page limitations described in $\langle u><i><a$ href="http://dx.doi.org/10.1061/978078447 9018" target="_blank">Publishing in ASCE Journals: A Guide for Authors $</ a></ u></ i>$. Technical papers and Case Studies must not exceed 30 double-spaced manuscript pages, including all figures and tables. Technical notes must not exceed 7 double-spaced manuscript pages. Papers that exceed the limits must be justified. Grossly overlength papers may be returned without review. Does this paper exceed the ASCE length limitations? If yes, please provide justification in the comments box below.

All authors listed on the manuscript must No have contributed to the study and must approve the current version of the manuscript. Are there any authors on the paper that do not meet these criteria? If the answer is yes, please explain in the comments. 
Was this paper previously declined or

withdrawn from this or another ASCE journal? If so, please provide the previous manuscript number and explain what you have changed in this current version in the comments box below. You may upload a separate response to reviewers if your comments are extensive.

Companion manuscripts are discouraged as all papers published must be able to stand on their own. Justification must be provided to the editor if an author feels as though the work must be presented in two parts and published simultaneously. There is no guarantee that companions will be reviewed by the same reviewers, which complicates the review process, increases the risk for rejection and potentially lengthens the review time. If this is a companion paper, please indicate the part number and provide the title, authors and manuscript number (if available) for the companion papers along with your detailed justification for the editor in the comments box below. If there is no justification provided, or if there is insufficient justification, the papers will be returned without review.

If this manuscript is intended as part of a Special Issue or Collection, please provide the Special Collection title and name of the guest editor in the comments box below.

Papers published in ASCE Journals must make a contribution to the core body of knowledge and to the advancement of the field. Authors must consider how their new knowledge and/or innovations add value to the state of the art and/or state of the practice. Please outline the specific contributions of this research in the comments box.

To read more about how the JCEM considers each paper's contributions please see the following Editor's Note.

JCEM strives to continually provide readers with the most relevant data and

\section{Not applicable}


research. Authors are asked to consider the impact of their research on the global construction community. Papers with a single-region focus should be submitted as a Case Study. Descriptions of a Case Study can be found in $<\mathrm{u}><\mathrm{i}><\mathrm{a}$ href="http://dx.doi.org/10.1061/978078447 9018" target="_blank">Publishing in ASCE Journals: A Guide for Authors $</ a\rangle</$ u $></ i>$. Does your paper contain research that is focused on a single region?

The flat fee for including color figures in print is $\$ 800$, regardless of the number of color figures. There is no fee for online only color figures. If you decide to not print figures in color, please ensure that the color figures will also make sense when printed in black-and-white, and remove any reference to color in the text. Only one file is accepted for each figure. Do you intend to pay to include color figures in print? If yes, please indicate which figures in the comments box.

The board of JCEM encourages authors to make data used in the current study available to other researchers in order to advance the science and profession. A Data Availability statement is required to appear at the end of the published paper. Please include this information in a section titled "Data Availability Statement" right before the acknowledgements. Please indicate below whether your data is available and how a reader may access the data. Note that selected statements will appear verbatim in your paper.

If there is anything else you wish to None communicate to the editor of the journal, please do so in this box.

Data generated or analyzed during the study are available from the corresponding author by request. 
A FOCUS GROUP STUDY TO EXPLORE CRITICAL FACTORS FOR MANAGING

STRESS OF THE CONSTRUCTION WORKERS

Qi Liang ${ }^{1}$, Mei-yung Leung ${ }^{2}$, Cary Cooper $^{3}$

ABSTRACT

7

Focus group studies were conducted to collect qualitative data from skilled CWs, general CWs, and supervisors of CWs. The study explored 15 coping behaviors (categorized as either problem-based or emotion-based), five emotional and 11 physical stress symptoms, and five indicators of CWs' performance and safety. The principal findings include: $C W s$ often not only experience physical stress symptoms, but also suffer from emotional stress symptoms; and unlike the managerial staffs, CWs usually adopt more emotion-based than

\footnotetext{
${ }^{1}$ Ph.D., Department of Architecture and Civil Engineering, City University of Hong Kong, Tat Chee Avenue, Kowloon Tong, Hong Kong; E-mail: qiliang3-c@my.cityu.edu.hk; Tel.: +852 3442 2641;

${ }^{2}$ Associate Professor, Department of Architecture and Civil Engineering, City University of Hong Kong, Tat Chee Avenue, Kowloon Tong, Hong Kong; E-mail:bcmei@cityu.edu.hk; Tel.: +852 3442 7142;

${ }^{3}$ Professor, ALLIANCE Manchester Business School, University of Manchester, E-mail: cary.cooper@manchester.ac.uk; Tel.: +44 (0)1612756371.
} 
problem-based coping behaviors (10 types and five types, respectively). A propositional model was proposed and validated by a short questionnaire survey study. Practical recommendations are made for promoting effective stress management and improving project management on CWs. The research limitations are discussed and suggestions for future research are made. This paper is the first attempt to explore CWs' coping behaviors, specific stress symptoms, and performance, which forms a basis for a future large-scale study.

\section{Keywords: Construction Workers; Focus Group; Health; Performance; Safety; Stress}

\section{INTRODUCTION}

Despite the application of advanced management methods and mechanization in the construction industry, the success of any construction project still largely depends on the performance of construction workers (CWs; Han et al. 2008). For instance, heavy equipment must be operated by CWs; and metal and wood joints must be handmade by them. Thus, it is critically important to improve CWs' performance in order to ensure the successful project management. However, CWs have to carry out tasks that are physically demanding (involving repetitive movements, heavy lifting, maintaining awkward postures, etc.) while under psychological pressure (with long working hours, job insecurity, deadlines to meet, etc.) and in challenging construction site environments (with extreme temperatures, excessive noise, air pollution, etc.). The unfavorable work characteristics and environment not only affect their productivity, but also result in high turnover rates and severe safety problems (Kazaz and Ulubeyli 2007; Leung et al. 2016). 
48 In fact, the construction industry is stressful for its participants (Chartered Institute of

49 Building 2006), especially for CWs; all over the world, they have been regarded as having

50 the one of the most stressful occupations (International Labour Organization 1992; Jacobsen et al. 2013). More than those in most other occupations (e.g., nurses, factory workers, teachers, etc.), CWs suffer from demanding work characteristics and face hostile environments (Hoonakker and Duivenbooden 2010). CWs work in dynamic site environments that are much affected by extreme weather; they work at very hazardous places on the construction site; and they work on projects whose schedules are usually very tight, but they rarely have opportunities for promotion within their own construction organization or even within the industry (Boschman et al. 2013; Gatti et al. 2013). Therefore, it may be incorrect to assume that CWs experience the same levels of stress and the same consequences of stress that empirical research has shown to affect individuals working in other jobs/professions.

The adoption of coping behaviors is the key to deciding whether various stress symptoms will result or not (Lazarus and Folkman 1984), while stress significantly affects individual's performance (e.g., Leung et al. 2006). The coping behaviors and its influence for construction professionals have been extensively researched (e.g., Haynes and Love 2004; Leung et al. 2006; Yip et al. 2008), while very few studies have explored CWs' coping behaviors. To fill in the research gap, it was necessary to conduct an empirical study exploring CWs' coping behaviors, specific stress symptoms, and performance at work. 


\section{LITERATURE REVIEW}

\section{Coping Behaviors}

Individuals normally experience appraisal processes in which they evaluate their capability, availability and resources to cope with stressful events, and proponents of the classical transactional model of stress and coping claim that appropriate coping behaviors can shield individuals from stress (Lazarus and Folkman 1984). Coping behaviors have been viewed as individuals' conscious efforts to manage conflicts between the demands on them and their resources (Haynes and Love 2004; Weiten and Lloyd 2009). Commonly identified coping behaviors in professions other than CWs (e.g., construction professionals, nurses and salesmen) include avoidance of stress, confrontive problem solving, emotional discharge, support seeking and so on (e.g., Haynes and Love 2004; Leung et al. 2015a).

During the coping process, several factors may influence an individual's selection of coping behaviors; these factors include personality, socioeconomic status, past experience, perceived level of stress, and occupation (Dewe and Cooper 2017; Leung et al. 2006, 2014; Ursin and Erikesen 2004). As stressful situations for CWs in real life are extremely complicated, it is hard to predict their coping behaviors simply from their work characteristics, stress levels and backgrounds. In general, coping behaviors can be broadly categorized as being either problem-based or emotion-based (Chan et al. 2012, 2016; Leung et al. 2006). Those belonging to the former category (i.e., problem-based coping behaviors) focus on addressing the source of stress (i.e., problems), while those belonging to the latter category (i.e., emotion-based coping behaviors) put efforts in regulating individuals' negative emotions (Folkman 2010). 


\section{Stress}

Stress is defined as the non-specific body response which appears as a result of frequent and/or continuous discrepancies between the demands on an individual and his/her ability to cope with the demands (Ganster and Rosen 2013; Lazarus 1990; Selye 1956). Stress can induce internal adjustments of the human body, and the adjustments may further develop into physical stress symptoms in response to chronic exposure (Ganster and Rosen 2013). Common physical stress symptoms in individuals include physical pain (headaches, back pain, etc.), eyestrain, and respiratory ailments (Nixon et al. 2011; Schat et al. 2005). It has also been claimed that various emotional stress symptoms, such as anxiety, tension, and depression, can also manifest in human beings as a result of continuously facing stressful events (e.g., Bryant 2013; Meliá and Becerril 2007).

\section{Performance}

The success of construction projects heavily depends on the performance of CWs in terms of cost, time and quality (e.g., Kazaz and Ulubeyli 2007). According to Campbell's performance model (Campbell et al. 1993), performance should concern the task proficiency of CWs (e.g., completion of the task in time, and job quality), the interrelationships between CWs and their co-workers (i.e., CWs need to work together as a team for completing complicated construction tasks), and their commitment to their organizations (e.g., related to the turnover rate, and shortage of manpower). In addition, safety is always one project objective, so CWs' safety performance should also be taken into account (Fung et al. 2005; Liao et al. 2015). 


\section{RESEARCH METHODOLOGY}

\section{Focus Groups}

Focus groups are widely used in qualitative research and have increasingly been used in research studies on health and safety (e.g., Asquin et al. 2010; Leung and Chan 2012). A focus group session is conducted in the form of a group discussion with a moderator/facilitator prompting the participants to exchange ideas, express their feelings, and describe their experiences in response to a set of questions on a certain topic (Cooper and Schindler 2006). A focus group has a group dynamic and brings several benefits to the gathering of data, including a synergistic group effect that stimulates discussion, with each participant reacting to or being inspired by the comments of the others; efficient use of time; substantial content generated from the discussion; observation by the mediator/researcher in a natural setting; and less mediator bias (Berg 2001; Conchie et al. 2013).

\section{Sample}

The research design and number of groups for a focus group study should be fit for data collection that best achieves the research purpose (e.g., Gamson 1992). The literature on CWs' occupational health and safety suggests that general CWs (GCWs) and skilled CWs (SCWs) have different rates of health and safety problems (Hess et al. 2004; Memarian and Mitropoulos 2013). Both GCWs and SCWs are under the supervision and management of their supervisors (site agent, foremen, etc.), who have deep insight into CWs' daily activities and behaviors. 
148 Although the number of participants in a focus group should be between two and 20, six to 10 149 participants are optimal for a study aiming to collect their true feelings and opinions 150 (Breakwell et al. 2006; Morgan 1996). In addition, a small group size allows each participant 151 more time to express his/her opinions and ideas. Hence, the current study recruited eight 152 SCWs for the SCW group, six GCWs for the GCW group, and 10 CSs for the CS group from different construction companies and projects.

As the targeted samples are CWs and their supervisors, purposive sampling was employed to select eligible participants based on the following criteria: 1) they were working in the mainstream construction industry (i.e., for developer, main contractor, subcontractor, supplier, etc.); 2) all of them had at least over six-months practical experience in the construction industry; and 3) the SCWs were registered tradesmen (e.g., concreters or bricklayers) and the CSs had experience managing CWs. Formal invitation letters were sent to the construction organizations and CSs by post and/or email. The CWs were assigned by their organization to participate in the study, and the authors recruited the CSs individually.

Around $44 \%$ of the participants were at least 50 years old, $26 \%$ were aged $40-49,26 \%$ were aged 30-39, and only $4 \%$ were aged 29 or under. Only one participant was female; this reflects the male-dominated nature of the industry (Rumens 2013). Almost all the

167 participants in the SCW and CS groups had amassed more than 10 years' work experience in the construction industry. The CWs' education level was generally low: the education of $70 \%$ of them ended after they had attended high school and the remaining $30 \%$ had had only a primary school education. As for the project types, over $80 \%$ of the participants were working on different building projects, $12.5 \%$ on various civil engineering projects, and the 
rest on alteration \& addition projects to existing buildings; these figures reflect the overall picture for the Hong Kong construction industry (Development Bureau 2015).

The participants in each group were relatively homogenous in terms of their role in construction projects, type of contract, gender, and so on. For instance, all the CWs were employed by subcontractors. However, it is interesting that all the SCWs were employed through subcontracting by subcontractors, while all the GCWs were directly employed by subcontractors. Perhaps, because of the recent boom in the construction industry and a serious shortage of skilled manpower (South China Morning Post 2014), SCWs have many job opportunities in the open market. Subcontracting enables them to work for several projects at the same time so as to maximize their income. On the other hand, construction organizations need to maintain a certain staffing level and employing GCWs is much cheaper than employing SCWs. Some intra-group differences - regarding age, work experience, project types, organizations, and so forth - were allowed in order to gather a wider range of views.

\section{Focus Group Study}

To facilitate the comparisons of the results, the same mediators posed a standardized set of semi-structured questions under the same framework with the identical procedure throughout all the three focus groups (Knodel 1993). The semi-structured questions cover four aspects: (1) CWs' emotional stress symptoms and how long these symptoms last; (2) CWs' physical stress symptoms and how long these symptoms last; (3) what CWs commonly do to relieve their stress and the effectiveness of these behaviors; and (4) the influence of stress on CWs' performance. As the manifestation of the stress symptoms is the result of chronic exposure to 
stressful events, the participants were asked how long they have been suffering one specific stress symptom during the focus group study (see above questions 1 and 2). The symptoms, which only emerged once or lasts very shortly (i.e., less than two days; Cardena et al. 2000), were not reported by the participants in current study. A short questionnaire was also used to collect the demographic information of the participants.

Each of the focus group studies was lasting for two and half hours to three hours. At the beginning of each focus group study, the mediator/researcher stated clearly the research purpose and the schedule for each session; the mediator/researcher also made it clear that everyone would have equal status and should have an equal voice, and that the participants should be free to express themselves without criticism. The participants were assured that all the information collected would be kept strictly confidential and would be used only for academic purposes (Berg 2001). In order to enhance mutual understanding among the participants who were generally not familiar with each other before the focus groups studies, and to create a relaxed and harmonious atmosphere, each participant was invited to make a self-introduction at beginning of each focus group study (Tracy et al. 2006).

The mediator/researcher used multiple resources to record the research results, including worksheets, immediate note-taking, videotaping, and a blackboard, in order to ensure the accuracy and reliability of the research results. The notes were doubled-checked by the participants during the focus group meetings and were reviewed by the author (who was also the focus group mediator) during the writing of this paper. To foster a group dynamic and prevent some voices dominating, the mediator/researcher intentionally gave the participants equal opportunities to speak. 
222

223

224

225

226

227

228

229

230

231

232

233

234

235

236

237

238

239

240

241

242

243

244

245

\section{Short Questionnaire Survey}

In order to cross-validate the qualitative data generated in the focus group, a short questionnaire survey was also conducted after the group discussion. The questionnaire was designed based on extensive literature review, and includes various validated scales for measuring coping behaviors, stress, performance and safety (e.g., Cardena et al. 2000; Folkman et al. 1986; Leung et al. 2015, 2016). A seven-point Likert scale, ranging from 1 (never/extremely disagree) to 7 (always/extremely agree), was used by the participants to reflect their individual opinion on the coping behaviors, stress, performance and safety factors. SPSS 22 was used to statistically analyze the collected data from questionnaire survey.

\section{CONTENT ANALYSIS, RESULTS AND DISCUSSION}

After the qualitative data collected from focus group studies and recorded by multiple sources (e.g., immediate notes, radio record, and so on), content analysis, which is one commonly used qualitative data analysis method, was employed to analyze the data in order to identify the collective opinions of the participants regarding the CWs' stress symptoms, coping behaviors and performance (Berg 2001; Hughes and DuMont 1993). Each of the participants' responses to specific question under the framework (e.g., their emotional stress symptoms) was closely examined by researchers. The common keywords and phrases in the statements made by the different participants were inductively identified, abstracted and further classified into different groups according to previous literature (e.g., stress symptoms groups, 
coping behaviors groups, and performance group). The interesting findings have been pointed out and discussed.

\section{Coping Behaviors of CWs}

In total, $15 \mathrm{CWs'}$ coping behaviors were explored through current focus group study. In accordance with the focus of the coping behaviors on either 'resolving source of stress' (i.e., problem-based coping) or 'regulation of negative emotions' (i.e., emotion-based coping), they can be categorized into two groups (see Table 1; Arciniega et al. 2008; Folkman 2010). The problem-based coping behaviors include seeking instrumental support (one excerpt; see number of " $\mathrm{x}$ " in Table 1), increasing wages (one excerpt), making positive reappraisals (one excerpt), negotiating (three excerpts), and relaxing (one excerpt); while the emotion-based coping behaviors include engaging in physical exercise (one excerpt), listening to music and playing games (two excerpts), gambling (three excerpts), consuming alcohol and smoking cigarettes (three excerpts), expressing negative feelings (one excerpt), using bad language (three excerpts), arguing and fighting (three excerpts), socializing (two excerpts), seeking family support (one excerpt), quitting(three excerpts), and self-controlling (three excerpts).

The results show that unlike their supervisors (e.g., project managers who used to adopt problem-based coping behaviors; Aitken and Crawford 2007; Leung et al. 2015a), the CWs generally tend to adopt more emotion-based (10 types; 25 excerpts) than problem-based coping behaviors (five types; seven excerpts) when suffering from stress. Moreover, it is interesting to find that only the CWs (both the SCWs and GCWs) reported that they adopt problem-based coping behaviors to cope with stress; while according to the CSs who are the 
271 SCWs and GCWs; and '0' excerpts reported by CSs in Table 1). This finding uncovered the

272 realistic situation that the CWs generally have very limited resources at work (e.g., less/no

273 power to make their work favorable for them; Stattin and Jarvholm 2005) and private life

274 (e.g., low socioeconomic statue; Ursin and Erikesen 2004), which prevents them from 275 adopting problem-based coping.

\section{Problem-based Coping Behaviors}

Planful problem solving behavior was not found being adopted by CWs for coping stress in current study, while it is the most commonly adopted problem-based coping behavior by

fact, this difference is understandable. The CWs often have very limited resources (e.g., power of decision making over their task) and knowledge (e.g., knowledge for effective problem solving) at work for resolving the complicated problems, and thus, prevent them from adoption of the planful problem solving behavior.

Construction tasks are normally too big and complicated for a single CW, and it is not uncommon for a $\mathrm{CW}$ to be stressed by difficulties they encounter in their work. Fortunately,

CWs often work in a team to complete a task. When they come across problems, they can then "resolve problems through seeking the help of friends who are able to deal with them" (SCW1). In addition, the construction industry and the management team have gradually adopted a mentor-mentee program among CWs (Hoffmeister et al. 2011); this allows junior and/or inexperienced CWs to seek advice and help from experienced/skilled CWs to resolve 
their problems. In fact, the behavior to seek support for resolving problem is the manifestation of instrumental support seeking behavior that has regarded as one of problembased coping.

Lacking an adequate co-worker, one SCW cannot complete his tasks on time and has long been criticized and pushed by his supervisor, which makes him very stressed. Hence, he said that he is going to "pay a high wage to employ a suitable co-worker, so as to complete the tasks as soon as possible" (SCW1). His remark indicates his intention to finish tasks (i.e., source of his stress) in the quickest way, despite the monetary cost. This is a manifestation of confrontive coping behavior; such behavior is defined as making aggressive efforts (e.g., taking risks) to change threatening situations (Penley et al. 2002).

Although CWs have limited knowledge and lack the necessary socioeconomic resources to change threatening situations at work, they can still adjust their perceptions. This study reveals that CWs adopt positive reappraisal to cope with stress. For instance, one SCW said, "After getting enough sleep, I can reappraise everything positively" (SCW4). Their being unable to change external circumstances forces CWs to cultivate the ability to adopt positive reappraisal as one way of coping. As perception of the stressful events largely decides the generation of stress consequences, positive reappraisal reduces the CWs' opportunity to suffer stress consequences.

It was found that-contrary to the public image of CWs as being passive, rude, and straightforward-CWs actively resolve their problems (i.e., actively address the sources of stress). While engaged on construction tasks, CWs "try to find a good way to resolve [problems]" (GCW5) and/or "negotiate with other CWs and try to resolve the problems" 
321 (SCW3; also mentioned by GCW2). Moreover, it is interesting to find that CWs understand

322 the negative influence of the demanding construction tasks and the hostile construction site

323 environment, and therefore intentionally make themselves relax. They often "intentionally

324 slow down and relax mind and body [after work]" (SCW6). These behaviors represent CWs'

325 active coping. In general, active coping leads to resolution of the stressful problems, well-

326 being and effective stress reduction (Haritatos et al. 2007). In summary, the five problem-

327 based coping behaviors were therefore further categorized into four subgroups: seeking

328 instrumental support, confrontive coping, positive reappraisal, and active coping (see Table

$3291)$.

Emotion-based Coping Behaviors

332

333

The results show that, in order to cope with their stress, CWs like to "do some physical exercises" and "listen to music and play computer games" (GCW3; also mentioned by GCW4); "express my negative emotions by talking to close friends" (GCW1 and SCW8); "use to have bad language" (SCW5; also mentioned by CS3 and CS7); they "like to gamble to relieve stress" (SCW2; also mentioned by GCW2 and CS2); and "smoke a lot when stressed" (GCW6; also mentioned by CS1). In addition, the CS group complained that "CWs often quarrel with their supervisor to relieve their stress" (CS5; also mentioned by CS6 and

CS8). All seven of these coping behaviors are an outlet for/to express CWs' unpleasant emotions, and they are therefore regarded as emotional discharge (Chan et al. 2014). However, emotional discharge may be ineffective in terms of stress management; even worse, it may exacerbate existing stress symptoms (e.g., Vallis and Leddin 2004). For instance, gambling may cause more stress to CWs, if they lose (SCW2). 
The participants reported that they liked to seek emotional support from their co-workers and friends when experiencing stress. For instance, CWs like to chat with their co-workers and socialize (e.g., go fishing, go out for dinner, etc.) with their friends (SCW5 and CS7). In addition, the family can help relieve CWs' stress. "My children give me the strength and energy to work and shield me from stress," said GCW1. Unlike instrumental support, which addresses the source of stress, emotional support can only regulate CWs' negative emotions (i.e., emotion-based in nature). Perhaps, although the CWs intend to seek supports for problem-solving, the support-providers (e.g., co-workers, family members and even supervisors who are often placed on the low level of the project management) are also lack of resources for resolving problems; instead, the support providers may just be able to help regulating the negative emotions of CWs through chats, sympathy and accompanies.

It was found that CWs think about finding another job when they suffer from stress. Suffering from stress leads many CWs to quit their job, as they think they "cannot carry on anymore" (SCW4) and should "find another job in the open market" (SCW5). One supervisor (CS3) commented that the high turnover of CWs is a manifestation of the escape strategy, which involves avoiding facing a stressful situation.

The participants also reported that CWs do not like to discuss their stress (GCW2 and GCW3). Most CWs are male and the main source of their family income. They think that telling their families about their stress can achieve nothing but only cause their family to worry (GCW3). At the same time, the construction industry usually has a traditional machismo culture, and it has been claimed that this culture also affects CWs' coping behaviors (Ankrah et al. 2009; Arciniega et al. 2009). As SCW6 put it, CWs do not admit to their stress because "that would show weakness." These responses to stress can be regarded 
as self-controlling behaviors, which suppresses the negative emotional reactions to stress (Leung et al. 2015a). In fact, the self-controlling behavior was also reported as one of the most commonly adopted emotion-based coping behaviors by the supervisor of CWs (e.g., project managers; Haynes and Love 2004). Adoption of the self-controlling behaviors both by CWs and their supervisors indicates the prevalence of the machismo culture in the industry.

\section{Stress Symptoms of CWs}

The present study revealed that CWs experience over ten stress symptoms. These symptoms are manifested either as physical stress symptoms (with 16 excerpts) or as emotional stress symptoms (with 14 excerpts; see Table 2).

\section{Physical Stress Symptoms of CWs}

\section{$<$ Table 2 >}

Physical pains are the most widely reported physical stress symptoms (eight excerpts; see Table 2); these include pains in the leg (two excerpts), waist (two excerpts), back (three excerpts), and fingers (one excerpt; GCW2, GCW4, GCW6, SCW2, and SCW6). Previous studies have regarded the pain experienced by $\mathrm{CWs}$ as a sign of musculoskeletal disorders (MSDs) and have attributed MSDs to strenuous physical activities, awkward work postures, and so on (e.g., Hess et al. 2004; Spielholz et al. 2006); however, it is interesting to know that physical pain may also be a manifestation of stress and this fact is supported by the observations of the focus group participants. The SCW and CS groups tried to explain how 
these physical stress symptoms are induced. One project manager (CS2) thought that heavy workloads cause the onset of back pain in CWs; and a skilled worker (SCW6) explained that "under stress, I unconsciously use excessive force, resulting in pain in the fingers". A CW may make bodily adjustments in response to external forces; for example, exerting more force with the leg in order to work faster. Long-lasting bodily adjustments without proper breaks may cause physical stress symptoms in the form of pains.

The participants of the focus group study reported that as a result of stress, CWs suffer eyestrain (one excerpt; SCW1), skin diseases (one excerpt; CS7), and lung problems (two excerpts; SCW6 and CS7). Moreover, it is first time to reveal that the prostate problem (one excerpt) prevalent among CWs may also be one of their physical stress symptoms. The problem was noted by the CS group. "If there is a common problem among CWs, it is a prostate problem. They very frequently go to the toilet" (CS1). Perhaps, the secretion of hormones in the brain affects the prostate gland; and if this occurs over a long period, prostate problems (such as prostate hyperplasia) result (Ullrich et al. 2005). Therefore, it is very likely that prostate problems are the physical manifestation of stress (e.g., Ko et al. 2005).

Other physical stress symptoms - including dizziness (one excerpt; CS7), sleep disorders (one excerpt; SCW3), and loss of appetite (one excerpt; SCW1) - were found in the CWs. While working on a hostile construction site environment, CWs perform physically and psychologically demanding tasks and they are distracted by interactions with others and by their own thoughts. "All of these cause CWs to become dizzy and thus cause accidents," reported one managerial staff (CS7). Stress also manifests itself in CWs as loss of appetite. The great time pressure imposed by supervisors and a lack of adequate co-workers to 
complete work tasks may exert stress on CWs that results in "loss of appetite" (SCW1). It is likely that external forces cause the secretion of hormones in the blood. Over a long period, excessive secretion of hormones causes an imbalance in the internal environment of the human body that is reflected in the form of dizziness, sleep disorders, and loss of appetite (Nixon et al. 2011).

\section{Emotional Stress Symptoms of CWs}

The CWs' stress were often ignored, because people used to claim that CWs mainly carry out various physical tasks on the construction site, and their health and safety problem may be solely caused by the physical factors (e.g., heavy materials handling, awkward posture, etc.; Sobeih et al. 2009). Interestingly, however, this study found that in addition to physical stress symptoms, CWs simultaneously experience five emotional stress symptoms (14 excerpts in total; see number of ' $x$ ' in Table 2), including anxiety (one excerpt), being angry (three excerpts), tension (two excerpts), listlessness (three excerpts) and worrying (five excerpts).

Anxiety was regarded as being an emotional stress symptom by the participants. SCW3 remarked, "My stress symptoms include anxiety, worrying, and being upset and angry." It is understandable that suffering from heavy workloads and severe physical demands can easily make CWs anxious. Getting upset and angry was also identified as a stress symptom by both the SCW and CS groups. The supervisors observed that it is very common for CWs to become upset and irritable, especially when criticized (CS2 and CS6). The SCW group added that stress induced their anger. As one SCW put it, "When I am under stress, I lose my temper, get upset, and use vulgar language" (SCW6). Finally, tension was identified by both 
the SCW and GCW groups as being an emotional stress symptom. Perhaps the tension is due to CWs' feelings of being unsafe when working on a construction site. "We are tense, and we have to spend a lot of emotional energy on thinking about our safety. This is because we know that we will be hurt or killed if we are not careful" (SCW6). It is likely that the three above mentioned symptoms are the instant results of suffering the demanding work characteristics (e.g., facing approaching deadline, uncomfortable construction site environment, rude behaviors of co-workers, and so on), which can disappear quickly as long as the source of stress is not available. For instance, they become relaxed after work (i.e., after leaving the site environment) and their tension disappeared (SCW5 and SCW6).

The CWs' tasks are often repetitive and monotonous (Gatti et al. 2013). "It is very rare for CWs to enjoy what they are doing. They just have to do what they have to do" (SCW5). The repetitiveness and monotony can result in stress to CWs that manifests itself as listlessness. The participants in both the SCW and GCW groups admitted that their work makes them feel listless because they have worked for a very long time, feel no passion for their work, and are bored with it (SCW4 and GCW6). Suffering from listlessness results in lack of motivation and may result in CWs' carelessness, which not only reduces their productivity but also increases their safety risks. All three focus groups observed that CWs continuously worry at work. For instance, GCW1 said, "I worry about money"; GCW3 worries that "girls don't like CWs"; and SCW1 continuously worries at work. The CSs also mentioned CWs' worrying in their focus group meeting. One CS said, "CWs may also worry at work because they do not have job security. They may work on one site today but on another site the next" (CS10). Such worrying by CWs may result from their inability to control their own jobs and lives to make them more favorable than unfavorable to them, because they lack knowledge and occupy the lower rungs of their organizations and even of society as a whole. 


\section{Performance of CWs}

472 As the CWs' performance is closely related to the success of construction project, the

473 participants were also asked to assess the CWs' performance under stress. Through the

474 focus group studies, five types of CWs' performance were explored, including quality of work (four excerpts; see the number of ' $x$ ' in Table 3), work speed (two excerpts), interpersonal relationships (three excerpts), intention to leave (three excerpts) and accidents (five excerpts). In accordance with Campbell's performance model (Campbell et al. 1993), the five performances were further classified into four groups, including task performance (including quality of work and work speed), interpersonal performance (interpersonal relationships with others), organizational performance (intention to leave), and safety performance (accidents). In general, it is interesting to find that, from the point of view of CS group, CWs perform poorly in all respects of performance (i.e., in task performance, interpersonal performance, organizational performance, and safety performance; see the excerpts of CSs in Table 3).

CWs' task performance has two aspects: the quality of the work and the speed at which the work is done. One $\mathrm{CW}$ expressed an attitude common among the CWs: "I keep the job quality as high as possible if I feel no stress" (GCW5); while their "quality of work is low" when they are suffering from stress. The CS group was generally dissatisfied with both the quality of CWs' work and the speed at which CWs work (CS3 and CS4), and they attributed CWs' poor performance to stress. One participant of the CS group made the observation that "stress distracts CWs and upsets them, leading to poor quality work" (CS4). Stress also slows down the speed at which CWs work, because stress causes them to be too "tense" to work (SCW4). If CWs can shield themselves from stress, they can "finish [their] tasks on 
time and well" (GCW2). In fact, it has been claimed that under stress, individuals used to become hasty, preoccupied by source of stress, and hard to concentrate on present tasks (e.g., Ganster and Rosen 2013), which definitely causes to the decreases in the quality and speed of CWs' performance.

\section{$<$ Table 3 >}

This study also reveals that CWs' interpersonal relationships deteriorate when they are under stress; this affects the success of a project (GCW2). One skilled CW admitted that stress harms his relationships with colleagues; he explained, "When I am stressed and worried, I do not want to speak to and often argue with my colleagues and I use a lot of bad language. All of which impairs the relationships I have with my colleagues" (SCW5). Worse still, the CS group reported that $\mathrm{CWs}$ fight each other on construction sites, due to their poor interpersonal relationships (CS2). Under stress, the CWs may become irritable, unreasonable, aggressive confrontive, and inpatient, which can definitely bring about higher opportunity of conflict and poor interpersonal relationships.

Stress was also found to be one reason why CWs leave a company. There was a consensus among the SCW and CS groups that once CWs became stressed, they quit their job and find another job in the open market (SCW1, CS2, and CS3). In fact, the links between construction companies and CWs are very weak: construction companies cannot offer CWs incentives other than payment, while the availability of other work opportunities and their stressful situation very often lead CWs to leave the industry. 
519 The participants reported that various stress symptoms (both emotional and physical ones) contribute to their accidents (e.g., hurrying - SCW6; feeling tense - GCW4; insufficient sleep

521

- GCW6). The CS group reported that "CWs always want to make thing easy and reduce their own workload, and they therefore often engage in unsafe practices" (CS9). However, it is likely that suffering from these stress symptoms make it hard for CWs to concentrate on their tasks and be aware of the potential safety hazards around. They may just want to finish their tasks as soon as possible in order to take rest early for alleviating their stress symptoms, and in this case, the safety hazards were often ignored and accidents are likely.

\section{THE PROPOSITIONAL MODEL}

New findings regarding the stress management of the CWs have been revealed through current study. Firstly, this study confirmed that the CWs suffer from both physical (11 types; 16 excerpts) and emotional stress symptoms (five types; 14 excerpts) in the realistic working context. The prostate problem was reported to be one of the physical stress symptoms; this problem has not been previously identified in other professions. CWs were found to adopt more emotion-based (23 excerpts) than problem-based (seven excerpts) coping behaviors, unlike their supervisors (e.g., construction professionals). This finding reflects the fact that CWs lack the resources to resolve their problems at work. Of the subgroups of coping behaviors, emotional discharge is the most widely adopted by CWs. It includes engaging in physical exercise, listening to music and playing games, gambling, consuming alcohol and smoking cigarettes, expressing negative feelings, using bad language, and arguing and fighting. The focus groups also explored four aspects of their performance that may be affected by stress: the speed and quality of their work (task performance), their interpersonal 
544 relationships (interpersonal performance), their intention to leave (organizational 545 performance), and their accident rates (safety performance).

546

547 To improve the current understanding of stress management for CWs and industrial practices

548 in the management of CWs, it is necessary to situate the current research results in previous 549 established theoretical models (Taylor et al. 2011), such as the coping behaviors-stress550 performance model for cost estimation (Leung et al. 2006) and the transactional stress 551 management model for the general population (Lazarus 1966). Therefore, based on current 552 research findings and literature, a propositional model for CWs' stress management has been 553 developed in this study (see Figure 1).

\section{Model Validation with Results of Short Questionnaire Survey}

The results of the short questionnaire survey are shown in below Table 4, including the mean value of the CWs' coping behaviors, stress, performance and safety. For the easy comparison in the results between focus group study and the short questionnaire survey, the number of excerpts resulting from focus group study regarding specific factor were also included in the Table 4. The comparison shows that the number of excerpts in focus group basically matches with the mean value in questionnaire survey (i.e., more excerpts associated with higher mean value for SCWs and GCWs, respectively). For instance, the SCWs, who have reported more physical stress than emotion stress in focus group (i.e., 7 vs 4 excerpts), shown higher mean value in physical stress than in emotional stress in questionnaire survey (i.e., 3.61 vs 3.10; see 
569

570

571

572

573

574

575

576

577

578

579

580

581

582

583

584

585

586

587

588

589

590

591 The current study explored CWs' coping behaviors, stress symptoms, and performance, and 592

593

coping in focus group study (i.e., 7 vs 2 excerpts), rated higher in emotion-based coping than in problem-based coping in questionnaire survey (i.e., 3.40 vs 2.90).

Although there are five excerpts in focus group for both SCWs' problem-based and emotionbased coping behaviors, the mean value of their problem-based coping is slightly higher than the mean value of emotion-based coping (i.e., $4.88-4.41=0.47$ ). It is obvious that the 'Instrumental Support Seeking' (5.50) largely contributes to the little differences. In fact, the high frequent adoption of 'Instrumental Support Seeking' by SCWs is understandable when taking their realistic situation into consideration. On one hand, the construction industry has long been adopting the mentor-mentee program among CWs, which allows CWs learn from others; on the other hand, the SCWs almost always work on similar/same tasks on the construction site, and the junior SCWs may encounter problems that were facing the senior SCWs before. Therefore, seeking instrumental support from experienced SCWs should be one effective and frequent way for SCWs to resolve problems.

\section{RECOMMENDATIONS}

\section{$<$ Table 4 >}

\section{Practical Implications}

proposed a propositional stress management model for them. A number of problems for CWs' stress management and performance have displayed by the proposed propositional 
594

595

596

597

598

599

600

601

602

603

604

605

606

607

608

609

610

611

612

613

614

615

616

617

model, such as adoption of more emotion-based than problem-based coping behaviors, various emotional and physical stress symptoms, and so on. Hence, it is recommended that construction organizations, the project management team, and CWs themselves take actions to manage the stress CWs experience and thus improve their performance.

This study reveals that CWs adopt more emotion-based than problem-based coping behaviors (23 excerpts vs. seven excerpts). As problem-based coping is generally adaptive in term of stress reduction, construction organizations and project management team should facilitate CWs' problem-based coping behaviors through provision of coping resources, such as providing coaching by supervisors, encouraging co-worker support, and delegation of job authority (e.g., Schaufeli and Bakker 2004). The establishment of hometown associations for CWs should enhance their mutual understanding and interpersonal relationships and thus facilitate co-worker support. Project management team should adopt a proactive management style, provide all necessary information and assistance to CWs to enable them to complete their tasks satisfactorily, and take CWs' abilities and preferences into account when assigning tasks to them.

As the results show, the participants subjectively judged the effectiveness of some of the coping behaviors. For instance, the CWs mentioned that they like to gamble to relieve their stress but they become more stressed if they lose money; and they are able to reappraise everything more positively after getting enough sleep. Project management team should educate CWs on the negative consequences of gambling and prohibit gambling by CWs on construction sites. In addition, because getting enough sleep helps CWs to recover their energy and affect their stress, construction companies and project management team should 
encourage CWs to go to bed and rise at regular times; promote the use of a sleep-monitor phone app by CWs; and help CWs who have sleep problems.

In the present study, CWs were found to suffer from both emotional and physical stress symptoms. Therefore, construction organizations and project management team should organize seminars and training workshops in stress management for their CWs. The seminars would enable CWs to understand how and why stress comes about and that how big a problem stress becomes depends on how CWs appraise it. These seminars would raise CWs' awareness of stress, which might increase CWs' resistance to stress. There are numerous training programs for managing stress, such as mindfulness-based stress reduction programs that cultivate individuals' mindfulness as a way of relieving stress (Bishop et al. 2004); somatic experiencing is a form of therapy for relieving mental and physical stress symptoms through focusing on physical sensations (Levine 1997); and Tai Chi has been found to be beneficial in promoting well-being and in managing stress (Sandlund and Norlander 2000).

Given the reported interaction between CWs' stress and their performance, necessary action should be taken to mitigate the negative effects of stress. For instance, the participants mentioned that the various stress symptoms cause CWs to engage in unsafe behaviors, leading to high accident rates. Construction organizations and project management team should, before every task and at the beginning of every day at work, remind CWs that if they feel stressed they should take a rest instead of persevering with the job in hand. CWs who have reported stress need the special attention and management of construction organizations, project management team, on-site nurses, and so on. 
643

644

645

646

647

648

649

650

651

652

653

654

655

656

657

658

659

660

661

662

663

664

665

666

667

\section{Research Limitations and Future Directions}

The data for this study was gathered from focus group studies, composed of SCWs, GCWs, and CSs groups. Given that every research method has potential biases (Webb et al. 1981), various actions were taken in current study to ensure the reliability of the research results: (1) a purposive sampling technique was used to ensure the suitability of the participants (e.g., they needed to have a certain amount of experience and have a specific trade); (2) standardized questions and procedures were applied to ensure comparability of the among groups; (3) the policy regarding confidentiality was announced at the beginning of the focus group sessions, so that the participants felt free to express their opinions; (4) to prevent some voices dominating, the mediator/researcher gave the participants equal opportunities to speak; (5) multiple resources were used to record the evidence, including note-taking during the sessions, voice recording, worksheets, and so on; (6) the participants were relatively homogeneous in each group, so that they had similar experiences of specific issues; (7) the purpose of the research was explained to the participants at the beginning of each focus group session, so they had a good understanding of what the mediator/researcher wanted to learn from them; and (8) the focus group studies involved skilled CWs, general CWs and their supervisors with different background (e.g., organization, employment types and project types), which ensures the representativeness of the study. In addition, the proposed propositional model has been validated by a short questionnaire survey study with quantitative data (i.e., between-methods triangulation; Berg 2001). In view of above, it is confident that the results of current study are reliable.

This study adopted a qualitative research method (i.e., focus group study) to realistically explore CWs' specific coping behaviors, stress symptoms, and performance, which are 
fundamental and necessary for the future research in relevant direction. However, it is

669

670

671

672

673

674

675

676

677

678

679

680

681

682

683

684

685

686

687

688

689

690

691 Stress stimulates physiological adjustments of the human body; and objective measurement 692 advocated that future study with different research methods (i.e., quantitative research methods like a questionnaire survey) could be conducted to investigate the interactions among the coping behaviors, stress symptoms, and performance of CWs. This would accord with the concept of methodological triangulation: the congruence of findings derived from different research methods ensures greater reliability and validity of the findings (Berg 2001). It is also necessary to conduct case studies for real construction projects and construction participants (i.e., in the form of individual interview), which will allow for the collection of detailed content information for validating the proposed stress management model for CWs in real projects (Fern 1982). Nevertheless, the current focus group study contributed to set up the necessary and important step for the future study (e.g., the design of the questionnaire and establishment of a propositional model) and improvement of current industrial practices.

The current study mainly set out to explore the coping behaviors, stress symptoms and performance of CWs in HK. As the adoption of the coping behaviors and generation of stress can be affected by situational factors, such as cultural value (e.g., individualism and collectivism; Schaubroeck et al. 2000), socioeconomic status in country (e.g., socioeconomic factors have larger effect on CWs in developing country than in developed country; Kazaz and Ulubeyli 2007), and so on, future study is recommended to focus on the differences in the stress management factors among CWs from different countries/districts. This sort of studies will definitely bring about benefits for the establishment of comprehensive stress management model for CWs.

\footnotetext{
of these physiological adjustments is viable with proper instruments, such as wristbands for
} 
693

694

695

696

697

698

699

700

701

702

703

704

705

706

707

708

709

710

711

712

713

714 As this study was aimed at exploring the participants' true opinions and feelings about their

715

716

717

measuring sleep patterns (Sharma and Gedeon 2012). In addition, the participation of the medical experts, such as dermatologist, pulmonologist, internist and so on, should ensure the correct identification of the various symptoms of CWs and enhance our understanding of the CWs' stress management. Hence, researchers with cross-disciplinary background and expertise are suggested to collaboratively adopt multiple research methods (i.e., including both quantitative questionnaires method and qualitative case studies method) and use various equipment and high-techs to validate the current research findings, and based on current findings, to establish a practical, realistic and comprehensive stress management model for CWs.

\section{CONCLUSION}

It has been widely recognized that CWs are vulnerable to various health and safety problems, have high turnover rates, and low productivity. Excessive stress has resulted in significant loss to individual CWs, the project management, construction organizations, and the industry as a whole. Although it is critical to manage CWs' stress through appropriate coping behavior, no previous study has explored the coping behaviors of CWs and very few studies have set out to explore CWs' stress symptoms and performance. The present study therefore set out to fill this research gap.

coping behaviors, stress, and performance, three focus group sessions (with a standardized set of questions and procedures) were conducted. It was found that 15 common coping behaviors are adopted by CWs to cope with stress. 10 of these are emotion-based coping 
behaviors; they are divided into four groups, including emotional discharge, emotional support seeking, escape, and self-controlling behaviors. The remaining five coping behaviors are problem-based; they are included in instrumental support seeking, confrontive coping, positive reappraisal, and active coping. Five emotional stress symptoms were explored, and 11 physical stress symptoms had eight aspects: physical pains, skin diseases, eyestrain, respiratory illnesses, prostate problems, dizziness, loss of appetite, and sleep disorders. Four aspects of the performance of CWs are affected by stress: task performance, interpersonal performance, organizational performance, and safety performance. A propositional model was established based on the results of focus group study, and it was validated through a short questionnaire survey study.

To manage stress and improve the performance of CWs, several recommendations are made, including the establishment of hometown associations; the application of a proactive management style; and organizing seminars and training workshops (such as a mindfulnessbased stress reduction program, somatic experiencing, and Tai Chi sessions). This study is the first to explore CWs' coping behaviors, stress symptoms, and performance. It can be used as the basis for establishing a comprehensive stress management model for CWs all over the world.

\section{ACKNOWLEDGMENT}

The work described in this paper was fully supported by a General Research Fund grant from the Research Grants Council of the Hong Kong Special Administrative Region, China [Project No. CityU 11202715]. 


\section{DATA AVAILABILITY STATEMENT}

Data generated or analyzed during the study are available from the corresponding author by request.

\section{REFERENCES}

Aitken, A., Crawford, L. (2007) Coping with stress: Dispositional coping strategies of project managers. International Journal of Project Management, 25(7), 666-673.

Ankrah, N.A., Proverbs, D., Debrah, Y. (2009) Factors influencing the culture of a construction project organisation: An empirical investigation. Engineering, Construction and Architectural Management, 16(1), 26-47.

Arciniega, G.M., Anderson, T.C., Tovar-Blank, Z.G., Tracey, T.J.G. (2008) Toward a fuller conception of machismo: Development of a traditional machismo and caballerismo scale. Journal of Counseling Psychology, 55(1), 19-33.

Asquin, A., Garel, G., Picq, T. (2010) When project-based management causes distress at work. International Journal of Project Management, 28(2), 166-172.

Berg, B.L. (2001) Qualitative Research Methods for the Social Sciences (4 ${ }^{\text {th }}$ eds.) Boston: Allyn and Bacon.

Bishop, S.R., Lau, M., Shapiro, S., Carlson, L., Anderson, N.D., Carmody, J., Segal, Z.V., Abbey, S., Speca, M., Velting, D., Devins, G. (2004) Mindfulness: a proposed operational definition. Clinical Psychology: Science and Practice, 11(3), 230-241.

Boschman, J.S., Van Der Molen, H.F., Sluiter, J.K., Frings-Dresen, M.H.W (2013) Psychosocial work environment and mental health among construction workers. Applied Ergonomics, 44(5), 748-755.

Breakwell, G.M., Hammond, S.M., Smith, J.A., Fife-Schaw, C., Smith J.A. (2006) Research Method in Psychology (3eds.). London: SAGE Publications Ltd.

Bryant, R.A. (2013) An update of acute stress disorder. PTSD Research Quarterly, 24(1), 1-7. Campbell, J.P., McCloy, R.A., Oppler, S.H., Sager, C.E. (1993) A theory of performance. In N. Schmitt and W.C. Borman (eds.). Personnel Selection in Organizations. San Francisco: Jossey-Bass.

Cardena, E., Koopman, C., Classen, C., Waelde, L.C., Spiegel, D. (2000) Psychometric properties of the Stanford Acute Stress Reaction Questionnaire (SASRQ): A valid and reliable measure of acute stress. Journal of Traumatic Stress, 13(4), 719-734.

Chan, I.Y.S., Leung, M.Y., Liu, A.M.M. (2016) Occupational health management system: A study of expatriate construction professionals. Accident Analysis and Prevention, 93, 280-290.

Chan, I.Y.S., Leung, M.Y., Yu, S.S.W. (2012) Managing the stress of Hong Kong expatriate construction professionals in mainland china: Focus group study exploring individual coping strategies and organizational support. Journal of Construction Engineering and Management, 138 (10), 1150-1160. 
Chan, I.Y.S., Leung, M.Y., Yuan, T. (2014) Structural relationships between cultural values and coping behaviors of professionals in the stressful construction industry. Engineering, Construction and Architectural Management, 21(2), 133-151.

Chartered Institute of Building (CIOB) (2006) Occupational Stress in the Construction Industry. Berkshire: CIOB.

Conchie, S.M., Moon, S., Duncan, M. (2013) Supervisors' engagement in safety leadership: Factors that help and hinder. Safety Science, 51, 109-117.

Cooper, D.R., Schindler, P.S. (2006) Business Research Methods ( $9^{\text {th }}$ eds.). New York: the McGraw-Hill.

Development Bureau (2015) Number of Manual Workers Engaged at Construction Sites. Retrieved

from: http://www.devb.gov.hk/en/publications_and_press_releases/figures_and_statistics/numb er_of_manual_workers/index.html, viewed on 19 August 2015.

Dewe, P.J. Cooper, C.L. (2017) Work Stress and Coping: Forces for Change and Challenges. London: Sage.

Fern, E.F. (1982) The use of focus groups for idea generation: The effects of group size, acquaintanceship, and moderator on a response quality and quantity. Journal of Marketing Research, 19, 1-13.

Folkman, S. (2010) Stress, coping, and hope. Psycho-Oncology, 19(9), 901-908.

Folkman, S., Lazarus, R.S., Dunkel-Schetter, C., DeLongis, A., Gruen, R.J. (1986) Dynamics of a stressful encounter: Cognitive appraisal, coping, and encounter outcomes. Journal of Personality and Social Psychology, 50(5), 992-1003.

Fung, I.W.H., Tam, C.M., Tung, K.C.F., Man, A.S.K. (2005) Safety cultural divergences among management, supervisory and work groups in Hong Kong construction industry. International Journal of Project Management, 23(7), 504-512.

Ganster, D.C., Rosen, C.C. (2013) Work stress and employee health: A multidisciplinary review. Journal of Management, 39(5), 1085-1117.

Gamson, W.A. (1992) Talking Politics. Cambridge: Cambridge University Press.

Gatti, U., Migliaccio, G., Bogus, S.M., Priyadarshini, S., Scharrer, A. (2013) Using workforce's physiological strain monitoring to enhance social sustainability of construction. Journal of Architectural Engineering, 19(3), 179-185.

Han, S., Park, S., Jin, E., Kim, H., Seong, Y. (2008) Critical issues and possible solutions for motivating foreign construction workers. Journal of Management in Engineering, 24(4), 217-226.

Haritatos, J., Mahalingam, R., James, R.A. (2007) John Henryism, self-reported physical health indicators, and the mediating role of perceived stress among high socio-economic status Asian immigrants. Social Science and Medicine, 64(6), 1192-1203.

Haynes, N.S., Love, P.E.D. (2004) Psychological adjustment and coping among construction project managers. Construction Management and Economics, 22(2), 129-140.

Hess, J.A., Hecker, S., Weinstein, M., Lunger, M. (2004) A participatory ergonomics intervention to reduce risk factors for low-back disorders in concrete laborers. Applied Ergonomics, 35(5), 427-441.

Hoffmeister, K., Cigularov, K.P., Sampson, J., Rosecrance, J.C., Chen, P.Y. (2011) A perspective on effective mentoring in the construction industry. Leadership and Organization Development Journal, 32(7), 673-688.

Hoonakker, P., Duivenbooden, C.V. (2010) Monitoring working conditions and health of older workers in Dutch construction industry. American Journal of Industrial Medicine, 53(6), 641-653.

Hughes, D., DuMont, K. (1993) Using focus groups to facilitate culturally anchored research. American Journal of Community Psychology, 21(6), 775-805. 
International Labour Organization (ILO) (1992) Preventing stress at work. In Di Martino, V. (ed.), Conditions of Work Digest. Geneva: ILO.

Jacobsen, H.B., Caban-Martinez, A., Onyebeke, L.C., Sorensen, G., Denneriein, J.T., Reme, S.E. (2013) Construction workers struggle with a high prevalence of mental distress, and this is associated with their pain and injuries. Journal of Occupational and Environment Medicine, 55(10), 1197-1204.

Kazaz, A., Ulubeyli, S. (2007) Drivers of productivity among construction workers: A study in a developing country. Building and Environment, 42(5), 2132-2140.

Knodel, J. (1993) The design and analysis of focus group studies: A practical approach. In D.L. Morgan. Successful Focus Groups: Advancing the State of the Art. Thousand Oaks: Sage.

Ko, C.M., Malcarne, V.L., Varni, J.W., Roesch, S.C., Rajni Banthia, H.L. (2005) Problemsolving and distress in prostate cancer patients and their spousal caregivers. Supportive Care in Cancer, 13(6), 367-374.

Lazarus, R.S. (1966) Psychological Stress and the Coping Process. New York: McGraw-Hill. Lazarus, R.S. (1990) Theory-based stress measurement. Psychological Inquiry, 1(1), 3-13.

Lazarus, R.S., Folkman, S. (1984) Stress, Appraisal, and Coping. New York: Springer.

Leung, M.Y., Chan, I.Y.S., Cooper, C.L. (2015) Stress Management in the Construction Industry. West Susses: John Wiley \& Sons.

Leung, M.Y., Liang, Q., Olomolaiye, P. (2016) Impact of job stressors and stress on the safety behaviour and accidents of construction workers. Journal of Management in Engineering, 32(1), 4015019.

Leung, M.Y., Liu, A.M.M., Wong, M.M.K. (2006) Impact of stress-coping behaviour on estimation performance. Construction Management and Economics, 24 (1), 55-67.

Levine, P.A. (1997) Waking the Tiger: Healing Trauma: The Innate Capacity to Transform Overwhelming Experiences. Berkeley, Calif.: North Atlantic Books.

Lewin, J.E., Sager, J.K. (2008) Salesperson burnout: A test of the coping-mediational model of social support. Journal of Personal Selling and Sales Management, 28(3), 233-246.

Liao, P.C., Lei, G., Xue, J.W., Fang, D.P. (2015) Influence of person-organizational fit on construction safety climate. Journal of Management in Engineering, 31(4), 4014049.

Memarian, B., Mitropoulos, P. (2013) Accidents in masonry construction: The construction of production activities to accidents, and the effect on different work groups. Safety Science, 59, 179-186.

Meliá, J., Becerril, M. (2007) Psychosocial sources of stress and burnout in the construction sector: A structural equation model. Psicothema, 19(4), 679-686.

Morgan, D.L. (1996) Focus group. Annual Review of Sociology, 22, 129-152.

Nixon, A.E., Mazzola, J.J., Bauer, J., Krueger, J.R., Spector, P.E. (2011) Can work make you sick? A meta-analysis of the relationships between job stressors and physical symptoms. Work and Stress, 25 (1), 1-22.

Penley, J.A., Tomaka, J., Wiebe, J.S. (2002) The Association of Coping to Physical and Psychological Health Outcomes: A Meta-Analytic Review. Journal of Behavioral Medicine, 25(6), 551-603.

Rumens, N. (2013) Queering men and masculinities in construction: Towards a research agenda. Construction Management and Economics, 31(8), 802-815.

Sandlund, E.S., Norlander, T. (2000) The effects of tai chi chuan relaxation and exercise on stress responses and well-being: An overview of research. International Journal of Stress Management, 7(2), 139-148.

Schat, A.C.H., Kelloway, E.K., Desmarais, S. (2005) The physical health questionnaire (PHQ). Construct validation of a self-report scale of somatic symptoms. Journal of Occupational Health Psychology, 10(4), 363-381. 
Schaubroeck, J., Lam, S.S., Xie, J.L. (2000) Collective efficacy versus self-efficacy in coping responses to stressors and control: a cross-cultural study. Journal of Applied Psychology, 85 (4), 512-525.

Schaufeli, W.B., Bakker, A.B. (2004) Job demands, job resources, and their relationship with burnout and engagement: A multi-sample study. Journal of Organizational Behavior, 25 (3), 293-315.

Selye, H. (1956) The Stress of Life. New York: McGraw Hill.

Sharma, N., Gedeon, T. (2012) Objective measures, sensors and computational techniques for stress recognition and classification: A survey. Computer Method and Programs in Biomedicine, 108(3), 1287-1301.

Sobeih, T., Salem, O., Genaidy, A., Abdelhamid, T., Shell, R (2009) Psychosocial factors and musculoskeletal disorders in the construction industry. Journal of Construction Engineering and Management, 135(4), 267-277.

South China Morning Post (2014) Skilled Workers in Short Supply in Hong Kong's Construction Industry. Retrieved from: http://www.scmp.com/property/hong-kongchina/article/1451437/skilled-workers-short-supply-construction-industry, viewed on 28 April 2014.

Spielholz, P., Davis, G., Griffith, J. (2006) Physical risk factors and controls for musculoskeletal disorders in construction trades. Journal of Construction Engineering and Management, 132 (10), 1059-1068.

Stattin, M., Jarvholm, B. (2005) Occupation, work environment, and disability pension: A prospective study of construction workers. Scandinavian Journal of Public Health, 33(2), 84-90.

Taylor, J.E., Dossick, C.S., Garvin, M. (2011) Meeting the burden of proof with case-study research. Journal of Construction Engineering and Management, 137(4), 303-311.

Tracy, S.J., Lutgen-Sandvik, P., Alberts, J.K. (2006) Nightmares, demons, and slaves: Exploring the plainful metaphors of workplace bullying. Management Communication Quarterly, 20(2), 148-185.

Ullrich, P.M., Lutgendorf, S.K., Leserman, J., Turesky, D.G., Kreder, K.J. (2005) Stress, hostility, and disease parameters of begin prostatic hyperplasia. Psychosomatic Medicine, 67(3), 476-482.

Ursin, H., Erikesen, H.R. (2004) The cognitive activation theory of stress. Psychoneuroendocrinology, 29(5), 567-592.

Vallis, T.M., Leddin, D. (2004) What makes Crohn's disease patients difficult to manage? The role of psychosocial factors. Journal of Clinical Psychology in Medical Settings, 11(4), 325-332.

Webb, E., Campbell, D., Schwartz, R., Sechrest, L., Grove, J. (1981) Nonreactive Measures in the Social Sciences. Boston, USA: Houghton Mifflin Company.

Weiten, W., Lloyd, M. (2009) Psychology Applied to Modern Life: Adjustment in the 21st Century. Australia: Belmont.

Yip, B., Rowlinson, S., Siu, O.L. (2008) Coping strategies as moderators in the relationship between role overload and burnout. Construction Management and Economics, 26 (8), 869-880. 
A Focus Group Study to Explore Critical Factors for Managing Stress of the Construction Workers

Table 1 Summary of CWs' Coping Behaviors

\begin{tabular}{|c|c|c|c|c|c|}
\hline \multirow{2}{*}{\multicolumn{2}{|c|}{ Coping Behaviors }} & \multicolumn{3}{|c|}{ Group } & \multirow[t]{2}{*}{ Excerpts from the transcripts } \\
\hline & & SCWs & GCWs & CS & \\
\hline \multicolumn{6}{|c|}{ Problem-based Coping } \\
\hline $\begin{array}{l}\text { 1. Seek inst'l } \\
\text { support }\end{array}$ & $\begin{array}{r}\text { Seek inst'l } \\
\text { support }\end{array}$ & $\mathrm{x}$ & & & $\begin{array}{l}\text { SCW1: I like to resolve problems through seeking } \\
\text { the help of friends who are able to deal with } \\
\text { them. }\end{array}$ \\
\hline $\begin{array}{l}\text { 2. Confrontive } \\
\text { coping }\end{array}$ & $\begin{array}{l}\text { Increase } \\
\text { wages }\end{array}$ & $\mathrm{x}$ & & & $\begin{array}{l}\text { SCW1: I am also going to pay a high wage to } \\
\text { employ a suitable co-worker so as to } \\
\text { complete the tasks as soon as possible. }\end{array}$ \\
\hline $\begin{array}{l}\text { 3. Positive } \\
\text { reappraisal }\end{array}$ & $\begin{array}{l}\text { Positively } \\
\text { reappraise }\end{array}$ & $\mathrm{x}$ & & & $\begin{array}{l}\text { SCW4: After getting enough sleep, I can reappraise } \\
\text { everything positively. }\end{array}$ \\
\hline \multirow[t]{4}{*}{ 4. Active coping } & 1 Negotiate & $\mathrm{x}$ & & & $\begin{array}{l}\text { SCW3: I will negotiate with other } C W s \text { and try to } \\
\text { resolve the problems. }\end{array}$ \\
\hline & & & $\mathrm{x}$ & & $\begin{array}{l}\text { GCW2: We negotiate with each other to resolve } \\
\text { problems. }\end{array}$ \\
\hline & & & $\mathrm{x}$ & & $\begin{array}{l}\text { GCW5: When I have problems at work, I find a } \\
\text { good way to resolve them myself. }\end{array}$ \\
\hline & 2 Relax & $\mathrm{x}$ & & & $\begin{array}{l}\text { SCW6: We relax after work. For example, we } \\
\text { intentionally slow down and relax mind and } \\
\text { body. }\end{array}$ \\
\hline \multicolumn{2}{|c|}{ Sub-total No. Excerpts (7) } & 5 & 2 & $\mathbf{0}$ & \\
\hline \multicolumn{6}{|c|}{ Emotion-based Coping } \\
\hline \multirow[t]{12}{*}{$\begin{array}{l}\text { 1. Emotional } \\
\text { discharge }\end{array}$} & $\begin{array}{l}\text { 1. Other } \\
\text { activities }\end{array}$ & & $\mathrm{x}$ & & $\begin{array}{l}\text { GCW3: I often do some physical exercises to relieve } \\
\text { my stress. I also listen to music, eat a lot, } \\
\text { and chat with my friends. }\end{array}$ \\
\hline & & & $\mathrm{x}$ & & $\begin{array}{l}\text { GCW4: I like to listen to music and play computer } \\
\text { games to relieve my stress. }\end{array}$ \\
\hline & 2. Gamble & $\mathrm{x}$ & $\mathrm{x}$ & & $\begin{array}{l}\text { SCW2: I like to gamble (handbookinger) to relieve } \\
\text { my stress. However, if I lose, I get even } \\
\text { more stressed. } \\
\text { GCW2: I play mahjong, eat a lot, smoke, and drink } \\
\text { when I feel stressed. }\end{array}$ \\
\hline & & & & $\mathrm{x}$ & $\begin{array}{l}\text { CS2: Gambling is the most common way for CWs to } \\
\text { cope with stress. }\end{array}$ \\
\hline & $\begin{array}{l}\text { 3. Drink } \\
\text { alcohol and } \\
\text { smoke }\end{array}$ & & $\mathrm{x}$ & $\mathrm{x}$ & $\begin{array}{l}\text { CS1: CW s consume alcohol after work, gamble, and } \\
\text { go to Shenzhen to relax. } \\
\text { GCW6: I smoked a lot when I was stressed in the } \\
\text { past. }\end{array}$ \\
\hline & $\begin{array}{l}\text { 4. Express } \\
\text { negative } \\
\text { feelings }\end{array}$ & & $\mathrm{x}$ & & $\begin{array}{l}\text { GCW1: I express my negative emotions out by } \\
\text { talking to close friends and seek their } \\
\text { support. }\end{array}$ \\
\hline & $\begin{array}{l}\text { 5. Use bad } \\
\text { language }\end{array}$ & $\mathrm{x}$ & & & $\begin{array}{l}\text { SCW5: I use to have bad language, complain, } \\
\text { consume alcohol, and go to Shenzhen to } \\
\text { relax. }\end{array}$ \\
\hline & & & & $\mathrm{x}$ & CS3: They use bad language at work. \\
\hline & & & & $\mathrm{x}$ & CS7: Bad language. \\
\hline & $\begin{array}{l}6 \text { Argue \& } \\
\text { fight }\end{array}$ & & $\mathrm{x}$ & & $\begin{array}{l}\text { GCW2: People usually argue and fight when they } \\
\text { are under stress. }\end{array}$ \\
\hline & & & & $\mathrm{x}$ & $\begin{array}{l}\text { CS5: Some CWs usually quarrel with their } \\
\text { supervisor to relieve their stress. }\end{array}$ \\
\hline & & & & $\mathrm{x}$ & $\begin{array}{c}\text { CS6: CWs don't like being criticized and often } \\
\text { argue with their supervisor. }\end{array}$ \\
\hline \multirow[t]{3}{*}{$\begin{array}{l}\text { 2. Emotional } \\
\text { support seeking }\end{array}$} & 1. Socialize & $\mathrm{x}$ & & & $\begin{array}{l}\text { SCW5: I also like to socialize with my friends and } \\
\text { have a few drinks. }\end{array}$ \\
\hline & & & & $\mathrm{x}$ & CS7: CWs like to go out and socialize. \\
\hline & $\begin{array}{l}\text { 2. Seek family } \\
\text { support }\end{array}$ & & $\mathrm{x}$ & & $\begin{array}{l}\text { GCW1: My children give me the strength and energy } \\
\text { to work and shield me from stress. }\end{array}$ \\
\hline
\end{tabular}


A Focus Group Study to Explore Critical Factors for Managing Stress of the Construction Workers

\begin{tabular}{|c|c|c|c|c|c|}
\hline \multirow[t]{2}{*}{ 3. Escape } & \multirow[t]{2}{*}{ Quit } & \multicolumn{3}{|l|}{$\mathrm{x}$} & $\begin{array}{l}\text { SCW4: I will leave the job the next day if I think I } \\
\text { cannot carry on any more. }\end{array}$ \\
\hline & & \multicolumn{2}{|l|}{$\mathrm{x}$} & $\mathrm{x}$ & $\begin{array}{l}\text { SCW5: I even want to quit my job, because I think I } \\
\text { can find another job outside the industry. } \\
\text { CS3: Because of all the job opportunities, CWs will } \\
\text { quit if they are criticized. }\end{array}$ \\
\hline $\begin{array}{l}\text { 4. Self- } \\
\text { controlling }\end{array}$ & Self-control & $\mathrm{x}$ & $\mathrm{x}$ & & $\begin{array}{l}\text { GCW 2: I do not talk to my family about my stress. } \\
\text { SCW 6: I do not talk to my friends and family, } \\
\text { because that would show weakness. } \\
\text { GCW 3: I do not like to talk to my family. I am a } \\
\text { man, the support of the family. I do not } \\
\text { want them to worry. }\end{array}$ \\
\hline Sub-total No & xcerpts $(23)$ & 6 & 9 & 8 & \\
\hline Total No. Ex & pts (30) & 11 & 11 & 8 & \\
\hline
\end{tabular}

Note: $\mathrm{SCWs}=$ skilled CWs; GCWs $=$ general CWs; CS = CWs' supervisors; $\mathrm{x}=$ excerpt 
Table 2 Summary of CWs' Stress Symptoms

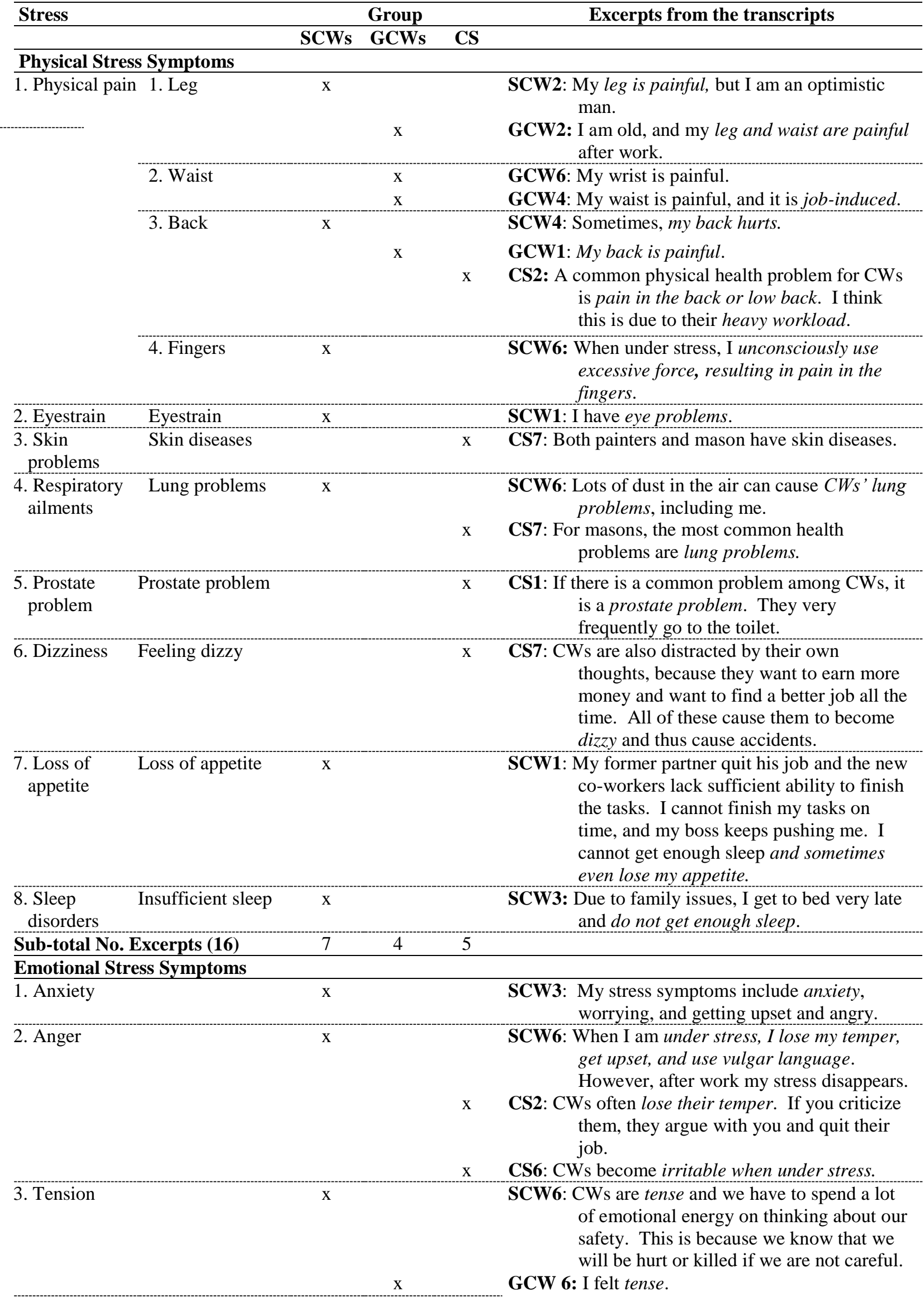




\begin{tabular}{|c|c|c|c|c|}
\hline 4. Listlessness & $\begin{array}{l}\mathrm{X} \\
\mathrm{X}\end{array}$ & $\mathrm{x}$ & & $\begin{array}{l}\text { SCW4: I am usually listless, as I get bored by my } \\
\text { job. } \\
\text { SCW5: It is very rare for CWs to enjoy what they } \\
\text { are doing. They just have to do what they } \\
\text { have to do. } \\
\text { GCW6: I have got accustomed to it, and my job } \\
\text { makes me feel numb. }\end{array}$ \\
\hline 5. Worrying & $\mathrm{x}$ & $\begin{array}{l}X \\
X \\
X\end{array}$ & $\mathrm{X}$ & $\begin{array}{l}\text { SCW1: I continuously worry at work. } \\
\text { GCW1: I worry about money. } \\
\text { GCW3: I just worry that girls don't like CWs. } \\
\text { GCW6: I worry, and this normally lasts for over a } \\
\text { week. } \\
\text { CS10: CWs may also worry at work because they } \\
\text { don't have job security. They may work } \\
\text { on one site today but on another site the } \\
\text { next. }\end{array}$ \\
\hline Sub-total No. Excerpts (14) & 6 & 5 & 3 & \\
\hline Total No. Excerpts (30) & 13 & 9 & 8 & \\
\hline
\end{tabular}

Note: $\mathrm{SCWs}=$ skilled CWs; GCWs = general CWs; CS = CWs' supervisors; $\mathrm{x}=$ excerpt 
Table 3 Summary of CWs' Performance

\begin{tabular}{|c|c|c|c|c|c|}
\hline \multicolumn{2}{|l|}{ Performance } & \multicolumn{3}{|c|}{ Group } & \multirow[t]{2}{*}{ Excerpts from the transcripts } \\
\hline & & SCWs & GCWs & $\mathbf{C S}$ & \\
\hline \multirow[t]{6}{*}{ 1. Task } & 1. Quality of & $\mathrm{x}$ & & & SCW3: My quality of work is low. \\
\hline & & & $\mathrm{x}$ & & $\begin{array}{l}\text { GCW5: I keep my job quality as high as possible, } \\
\text { if I feel no stress. }\end{array}$ \\
\hline & & & & $\mathrm{x}$ & CS3: I am not satisfied by CWs’ performance. \\
\hline & & & & $\mathrm{x}$ & $\begin{array}{c}\text { CS4: Dissatisfaction. Stress definitely affects } C W s \text {, } \\
\text { performance. Stress distracts CWs, upsets } \\
\text { them, leading to work of poor quality. }\end{array}$ \\
\hline & 2. Work speed & $\mathrm{x}$ & & & $\begin{array}{l}\text { SCW4: When I am tense, my work speed slows } \\
\text { down. My boss will then criticize me, and } \\
\text { that increases my stress. }\end{array}$ \\
\hline & & & $\mathrm{x}$ & & $\begin{array}{l}\text { GCW2: I don't feel any stress. I can finish my } \\
\text { tasks on time and well. }\end{array}$ \\
\hline \multicolumn{2}{|c|}{ Sub-total No. Excerpts (6) } & 2 & 2 & 2 & \\
\hline \multirow[t]{3}{*}{ 2. Interpersonal } & $\begin{array}{l}\text { Interpersonal } \\
\text { relationships }\end{array}$ & $\mathrm{x}$ & & & $\begin{array}{l}\text { SCW5: Stress definitely affects my interpersonal } \\
\text { relationships. When I am stressed and } \\
\text { worried, I do not want to speak, I often } \\
\text { argue with my colleagues, and I use a lot } \\
\text { of bad language. }\end{array}$ \\
\hline & & & $\mathrm{x}$ & & $\begin{array}{l}\text { GCW2: I don't feel any stress, and therefore have } \\
\text { close relationships with my colleagues. }\end{array}$ \\
\hline & & & & $\mathrm{x}$ & CS2: CWs also fight on construction sites. \\
\hline \multicolumn{2}{|c|}{ Sub-total No. Excerpts (3) } & 1 & 1 & 1 & \\
\hline \multirow[t]{3}{*}{ 3. Organizational } & $\begin{array}{l}\text { Intention to } \\
\text { leave }\end{array}$ & $\mathrm{x}$ & & & $\begin{array}{l}\text { SCW1: When I am under stress, I want to leave the } \\
\text { company and find another job. }\end{array}$ \\
\hline & & & & $\mathrm{x}$ & $\begin{array}{l}\text { CS2: If you criticize them, they will argue against } \\
\text { you and even quit their job. }\end{array}$ \\
\hline & & & & $\mathrm{x}$ & $\begin{array}{c}\text { CS3: Because of all the job opportunities there are, } \\
\text { CWs will quit if they are criticized. }\end{array}$ \\
\hline \multicolumn{2}{|c|}{ Sub-total No. Excerpts (3) } & 1 & & 2 & \\
\hline \multirow[t]{5}{*}{ 4. Safety } & Accidents & $\mathrm{x}$ & & & $\begin{array}{l}\text { SCW6: When I am under stress, I rush things at } \\
\text { work, which increases the risk of an } \\
\text { accident. }\end{array}$ \\
\hline & & $\mathrm{x}$ & & & $\begin{array}{l}\text { SCW1: Both physical and mental health problems } \\
\text { lead to more accidents. }\end{array}$ \\
\hline & & & $\mathrm{x}$ & & $\begin{array}{l}\text { GCW4: Feeling stressed at work also results in } \\
\text { accidents. }\end{array}$ \\
\hline & & & $\mathrm{x}$ & & GCW6: Insufficient sleep leads to accidents. \\
\hline & & & & $\mathrm{x}$ & $\begin{array}{l}\text { CS9: CWs always want to make thing easy and } \\
\text { reduce their own workload, and therefore } \\
\text { often engage in unsafe practices. }\end{array}$ \\
\hline \multicolumn{2}{|c|}{ Sub-total No. Excerpts (5) } & 2 & 2 & 1 & \\
\hline \multicolumn{2}{|l|}{ Total No. Ref. } & 6 & 5 & 6 & \\
\hline
\end{tabular}

Note: $\mathrm{SCWs}=$ skilled CWs; GCWs = general CWs; CS = CWs' supervisors; $\mathrm{x}=$ excerpt 
Table 4 Mean of Coping Behaviors, Stress, Performance and Safety for Construction Workers

\begin{tabular}{|c|c|c|c|c|c|c|}
\hline \multirow{3}{*}{$\begin{array}{c}\text { Coping Behaviors, Stress, } \\
\text { Performance \& Safety }\end{array}$} & \multicolumn{3}{|c|}{ SCWS } & \multicolumn{3}{|c|}{ GCWs } \\
\hline & \multirow{2}{*}{$\begin{array}{c}\text { FG } \\
\text { (no. of } \\
\text { excerpt) }\end{array}$} & \multicolumn{2}{|c|}{ Questionnaire } & \multirow{2}{*}{$\begin{array}{c}\text { FG } \\
\text { (no. of } \\
\text { excerpt) }\end{array}$} & \multicolumn{2}{|c|}{ Questionnaire } \\
\hline & & Mean & S.D. & & Mean & S.D. \\
\hline \multicolumn{7}{|l|}{ Problem-based coping } \\
\hline 1. Instrumental support seeking & 1 & 5.50 & 1.08 & & 3.30 & 1.96 \\
\hline 2. Confrontive coping & 1 & 4.43 & 1.72 & & 2.60 & 2.30 \\
\hline 3. Positive reappraisal & 1 & 4.93 & 1.21 & & 2.50 & 1.54 \\
\hline 4. Active coping & 2 & 4.64 & 1.21 & 2 & 3.20 & 1.15 \\
\hline Sum (FG) / Average (Ques.) & 5 & 4.88 & & 2 & 2.90 & \\
\hline \multicolumn{7}{|l|}{ Emotion-based coping } \\
\hline 5. Emotional discharge & 2 & 4.19 & 1.15 & 6 & 2.93 & 1.37 \\
\hline 6. Emotional support seeking & 1 & 5.05 & 1.77 & 1 & 4.27 & 1.99 \\
\hline 7. Escape & 2 & 4.00 & 1.91 & & 3.00 & 1.73 \\
\hline Sum (FG) / Average (Ques.) & 5 & 4.41 & & 7 & $\mathbf{3 . 4 0}$ & \\
\hline \multicolumn{7}{|l|}{ Physical stress } \\
\hline 8. Physical pains & 4 & 3.86 & 1.56 & 4 & 2.78 & 1.31 \\
\hline 9. Breath problem & 1 & 4.14 & 2.48 & & 2.00 & 1.26 \\
\hline 10.Dizziness & & 3.57 & 2.15 & & 2.33 & 1.75 \\
\hline 11. Lost appetite & 1 & 3.17 & 1.72 & & 2.17 & 1.47 \\
\hline 12. Sleep problem & 1 & 3.86 & 2.19 & & 2.50 & 2.07 \\
\hline Sum (FG) / Average (Ques.) & 7 & 3.61 & & 4 & 2.35 & \\
\hline \multicolumn{7}{|l|}{ Emotional stress } \\
\hline 13. Tension & 1 & 3.29 & 1.70 & 1 & 2.17 & 1.47 \\
\hline 14. Listlessness & 2 & 2.57 & 1.51 & 1 & 2.33 & 1.51 \\
\hline 15. Worry & 1 & 3.43 & 2.23 & 3 & 2.67 & 1.51 \\
\hline Sum (FG) / Average (Ques.) & 4 & 3.10 & & 5 & 2.39 & \\
\hline \multicolumn{7}{|l|}{ Performance } \\
\hline 16. Task performance & 2 & 4.52 & 0.94 & 2 & 3.28 & 0.93 \\
\hline 17. Interpersonal performance & 1 & 4.10 & 0.50 & 1 & 4.61 & 0.65 \\
\hline 18. Turnover intention & 1 & 3.90 & 1.47 & & 1.83 & 1.33 \\
\hline Sum (FG) / Average (Ques.) & 4 & 4.17 & & 3 & 3.24 & \\
\hline \multicolumn{7}{|l|}{ Safety } \\
\hline 19. Unsafe behaviors \& accidents & 2 & 3.14 & 1.23 & 2 & 2.58 & 0.83 \\
\hline Sum (FG) / Average (Ques.) & 2 & 3.14 & & 2 & 2.58 & \\
\hline
\end{tabular}

Note: $\mathrm{FG}=$ Focus group; $\mathrm{SCWs}=$ skilled CWs; GCWs $=$ general CWs; CSs = CWs' supervisors 
A Focus Group Study to Explore Critical Factors for Managing Stress of the Construction Workers

\begin{tabular}{|l||}
\hline \multicolumn{1}{|c|}{ Stress } \\
\hline Emotional (14Es) \\
Anxiety (1E) \\
Anger (3Es) \\
Tension (2Es) \\
Listlessness (3Es) \\
Worrying (5Es) \\
\hline Physical (16Es) \\
Physical pain (8Es) \\
Eyestrain (1E) \\
Skin disease (1E) \\
Respiratory (2Es) \\
Prostate (1E) \\
Dizziness (1E) \\
Appetite (1E) \\
Sleep disorder (1E) \\
\hline
\end{tabular}

\begin{tabular}{|l|}
\hline \multicolumn{1}{|c|}{ Coping Behaviors } \\
Problem-based (7Es) \\
See instrumental support (1E) \\
Confrontive coping (1E) \\
Positive reappraisal (1E) \\
Active coping (4Es) \\
Emotion-based (23Es) \\
Emotional discharge (14Es) \\
Emotional support seeking (3Es) \\
Escape (3Es) \\
Self-controlling (3Es) \\
\hline
\end{tabular}

\begin{tabular}{|l|}
\hline \multicolumn{1}{|c|}{ Performance } \\
Task performance (6Es) \\
Interpersonal performance (3Es) \\
Organizational performance (3Es) \\
Safety performance (5Es)
\end{tabular}


Figure 1 Propositional Coping Behaviors-Stress-Performance Model for CWs

Note: $E=$ Excerpt 


\title{
ASCE Authorship, Originality, and Copyright Transfer Agreement
}

\author{
Publication Title: Journal of Construction Engineering and Management \\ Manuscript Title: A FOCUS GROUP STUDY TO EXPLORE CRITICAL FACTORS FOR MANAGING STRESS OF THE CONSTRUCTION WORKERS
}

Author(s) - Names, postal addresses, and e-mail addresses of all authors

Qi Liang; Department of Architecture and Civil Engineering, City University of Hong Kong, Tat Chee Avenue, Kowloon Tong, Hong Kong; E-mail: qiliang3-c@my.cityu.edu.hk

Mei-yung Leung; Department of Architecture and Civil Engineering, City University of Hong Kong, Tat Chee Avenue, Kowloon Tong, Hong Kong; E-mail: bcmei@cityu.edu.hk

Cary Cooper; Manchester Business School, University of Manchester, E-mail: cary.cooper@manchester.ac.uk

\section{Authorship Responsibility}

To protect the integrity of authorship, only people who have significantly contributed to the research or project and manuscript preparation shall be listed as coauthors. The corresponding author attests to the fact that anyone named as a coauthor has seen the final version of the manuscript and has agreed to its submission for publication. Deceased persons who meet the criteria for coauthorship shall be included, with a footnote reporting date of death. No fictitious name shall be given as an author or coauthor. An author who submits a manuscript for publication accepts responsibility for having properly included all, and only, qualified coauthors.

I, the corresponding author, confirm that the authors listed on the manuscript are aware of their authorship status and qualify to be authors on the manuscript according to the guidelines above.

\begin{tabular}{lll} 
Mei-yung Leung & 19-Sep-2017 \\
\hline Print Name & Dignature
\end{tabular}

\section{Originality of Content}

ASCE respects the copyright ownership of other publishers. ASCE requires authors to obtain permission from the copyright holder to reproduce any material that (1) they did not create themselves and/or (2) has been previously published, to include the authors' own work for which copyright was transferred to an entity other than ASCE. Each author has a responsibility to identify materials that require permission by including a citation in the figure or table caption or in extracted text. Materials re-used from an open access repository or in the public domain must still include a citation and URL, if applicable. At the time of submission, authors must provide verification that the copyright owner will permit re-use by a commercial publisher in print and electronic forms with worldwide distribution. For Conference Proceeding manuscripts submitted through the ASCE online submission system, authors are asked to verify that they have permission to re-use content where applicable. Written permissions are not required at submission but must be provided to ASCE if requested. Regardless of acceptance, no manuscript or part of a manuscript will be published by ASCE without proper verification of all necessary permissions to re-use. ASCE accepts no responsibility for verifying permissions provided by the author. Any breach of copyright will result in retraction of the published manuscript.

I, the corresponding author, confirm that all of the content, figures (drawings, charts, photographs, etc.), and tables in the submitted work are either original work created by the authors listed on the manuscript or work for which permission to reuse has been obtained from the creator. For any figures, tables, or text blocks exceeding 100 words from a journal article or 500 words from a book, written permission from the copyright holder has been obtained and supplied with the submission.

$\frac{\text { Mei-yung Leung }}{\text { Print name }}$

\section{Copyright Transfer}

ASCE requires that authors or their agents assign copyright to ASCE for all original content published by ASCE. The author(s) warrant(s) that the above-cited manuscript is the original work of the author(s) and has never been published in its present form. 
The undersigned, with the consent of all authors, hereby transfers, to the extent that there is copyright to be transferred, the exclusive copyright interest in the above-cited manuscript (subsequently called the "work") in this and all subsequent editions of the work (to include closures and errata), and in derivatives, translations, or ancillaries, in English and in foreign translations, in all formats and media of expression now known or later developed, including electronic, to the American Society of Civil Engineers subject to the following:

- The undersigned author and all coauthors retain the right to revise, adapt, prepare derivative works, present orally, or distribute the work, provided that all such use is for the personal noncommercial benefit of the author(s) and is consistent with any prior contractual agreement between the undersigned and/or coauthors and their employer(s).

- No proprietary right other than copyright is claimed by ASCE.

- If the manuscript is not accepted for publication by ASCE or is withdrawn by the author prior to publication (online or in print), or if the author opts for open-access publishing during production (journals only), this transfer will be null and void.

- Authors may post a PDF of the ASCE-published version of their work on their employers' Intranet with password protection. The following statement must appear with the work: "This material may be downloaded for personal use only. Any other use requires prior permission of the American Society of Civil Engineers."

- Authors may post the final draft of their work on open, unrestricted Internet sites or deposit it in an institutional repository when the draft contains a link to the published version at www. ascelibrary.org. "Final draft" means the version submitted to ASCE after peer review and prior to copyediting or other ASCE production activities; it does not include the copyedited version, the page proof, a PDF, or full-text HTML of the published version.

Exceptions to the Copyright Transfer policy exist in the following circumstances. Check the appropriate box below to indicate whether you are claiming an exception:

U.S. GOVERNMENT EMPLOYEES: Work prepared by U.S. Government employees in their official capacities is not subject to copyright in the United States. Such authors must place their work in the public domain, meaning that it can be freely copied, republished, or redistributed. In order for the work to be placed in the public domain, ALL AUTHORS must be official U.S. Government employees. If at least one author is not a U.S. Government employee, copyright must be transferred to ASCE by that author.

CROWN GOVERNMENT COPYRIGHT: Whereby a work is prepared by officers of the Crown Government in their official capacities, the Crown Government reserves its own copyright under national law. If ALL AUTHORS on the manuscript are Crown Government employees, copyright cannot be transferred to ASCE; however, ASCE is given the following nonexclusive rights: (1) to use, print, and/or publish in any language and any format, print and electronic, the above-mentioned work or any part thereof, provided that the name of the author and the Crown Government affiliation is clearly indicated; (2) to grant the same rights to others to print or publish the work; and (3) to collect royalty fees. ALL AUTHORS must be official Crown Government employees in order to claim this exemption in its entirety. If at least one author is not a Crown Government employee, copyright must be transferred to ASCE by that author.

$\square$ WORK-FOR-HIRE: Privately employed authors who have prepared works in their official capacity as employees must also transfer copyright to ASCE; however, their employer retains the rights to revise, adapt, prepare derivative works, publish, reprint, reproduce, and distribute the work provided that such use is for the promotion of its business enterprise and does not imply the endorsement of ASCE. In this instance, an authorized agent from the authors' employer must sign the form below.

U.S. GOVERNMENT CONTRACTORS: Work prepared by authors under a contract for the U.S. Government (e.g., U.S. Government labs) may or may not be subject to copyright transfer. Authors must refer to their contractor agreement. For works that qualify as U.S. Government works by a contractor, ASCE acknowledges that the U.S. Government retains a nonexclusive, paid-up, irrevocable, worldwide license to publish or reproduce this work for U.S. Government purposes only. This policy DOES NOT apply to work created with U.S. Government grants.

I, the corresponding author, acting with consent of all authors listed on the manuscript, hereby transfer copyright or claim exemption to transfer copyright of the work as indicated above to the American Society of Civil Engineers.

\section{Mei-yung Leung}

Print Name of Author or Agent

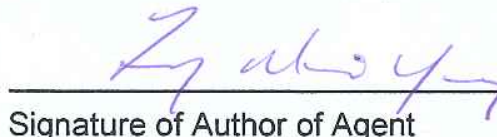

19-Sep-2017

Signature of Author of Agent

More information regarding the policies of ASCE can be found at http://www.asce.org/authorsandeditors 
$19^{\text {th }}$ September 2017

Journal of Construction Engineering and Management

College of Science and Engineering

Department of Architecture and Civil Engineering

Dear Sir /Madam,

\section{A FOCUS GROUP STUDY TO EXPLORE CRITICAL FACTORS FOR MANAGING STRESS OF THE CONSTRUCTION WORKERS}

Further to your letter dated $31^{\text {st }}$ August 2017 regarding the captioned paper, we have amended the paper in accordance to the reviewers' comments. A summary of our responses to these comments is listed as below.

\begin{tabular}{|c|c|c|}
\hline & Reviewer's comments & Responses \\
\hline & Reviewer 1 & \\
\hline 1 & $\begin{array}{l}\text { The manuscript has been } \\
\text { improved and most comments } \\
\text { have been addressed. }\end{array}$ & Thanks a lot for your comment. \\
\hline 2 & $\begin{array}{l}\text { It is suggested to adopt more } \\
\text { research methods, and conduct } \\
\text { additional research work (e.g. } \\
\text { model validation using } \\
\text { questionnaires). }\end{array}$ & $\begin{array}{l}\text { Revised 'Short Questionnaire Survey' section (see page 10) } \\
\text { "In order to cross-validate the qualitative data generated in the focus group, a } \\
\text { short questionnaire survey was also conducted after the group discussion. The } \\
\text { questionnaire was designed based on extensive literature review, and includes } \\
\text { various validated scales for measuring coping behaviors, stress, performance } \\
\text { and safety (e.g., Cardena et al. 2000; Folkman et al. 1986; Leung et al. 2015, } \\
2016 \text { ). A seven-point Likert scale, ranging from } 1 \text { (never/extremely disagree) } \\
\text { to } 7 \text { (always/extremely agree), was used by the participants to reflect their } \\
\text { individual opinion on the coping behaviors, stress, performance and safety } \\
\text { factors. SPSS } 22 \text { was used to statistically analyze the collected data from } \\
\text { questionnaire survey." }\end{array}$ \\
\hline
\end{tabular}

Revised 'Model Validation with Results of Short Questionnaire Survey' section (see pages 23-24; also see Table 4)

"The results of the short questionnaire survey are shown in below Table 4, including the mean value of the CWs' coping behaviors, stress, performance and safety. For the easy comparison in the results between focus group study and the short questionnaire survey, the number of excerpts resulting from focus group study regarding specific factor were also included in the Table 4 . The comparison shows that the number of excerpts in focus group basically matches with the mean value in questionnaire survey (i.e., more excerpts associated with higher mean value for SCWs and GCWs, respectively). For instance, the SCWs, who have reported more physical stress than emotion stress in focus group (i.e., 7 vs 4 excerpts), shown higher mean value in physical stress than in emotional stress in questionnaire survey (i.e., 3.61 vs 3.10; see Table 4); and the GCWs, who reported more emotion-based coping than problem-based coping in focus group study (i.e., 7 vs 2 excerpts), rated higher in emotionbased coping than in problem-based coping in questionnaire survey (i.e., 3.40 vs 2.90).

Although there are five excerpts in focus group for both SCWs' problem-based and emotion-based coping behaviors, the mean value of their problem-based coping is slightly higher than the mean value of emotion-based coping (i.e., 4.88 $4.41=0.47$ ). It is obvious that the 'Instrumental Support Seeking' (5.50) largely contributes to the little differences. In fact, the high frequent adoption of 'Instrumental Support Seeking' by SCWs is understandable when taking their realistic situation into consideration. On one hand, the construction industry has long been adopting the mentor-mentee program among CWs, which allows CWs learn from others; on the other hand, the SCWs almost always work on 


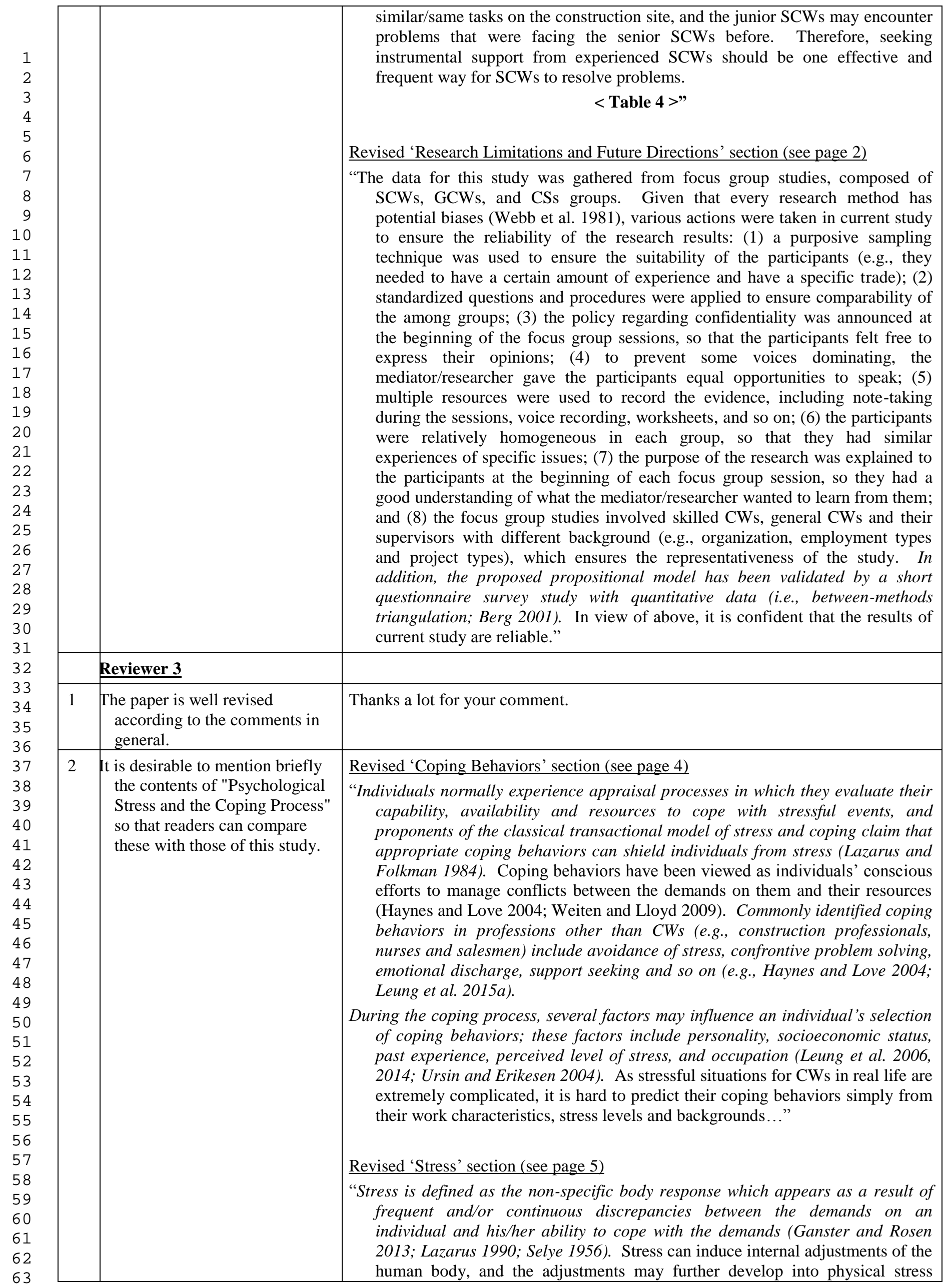




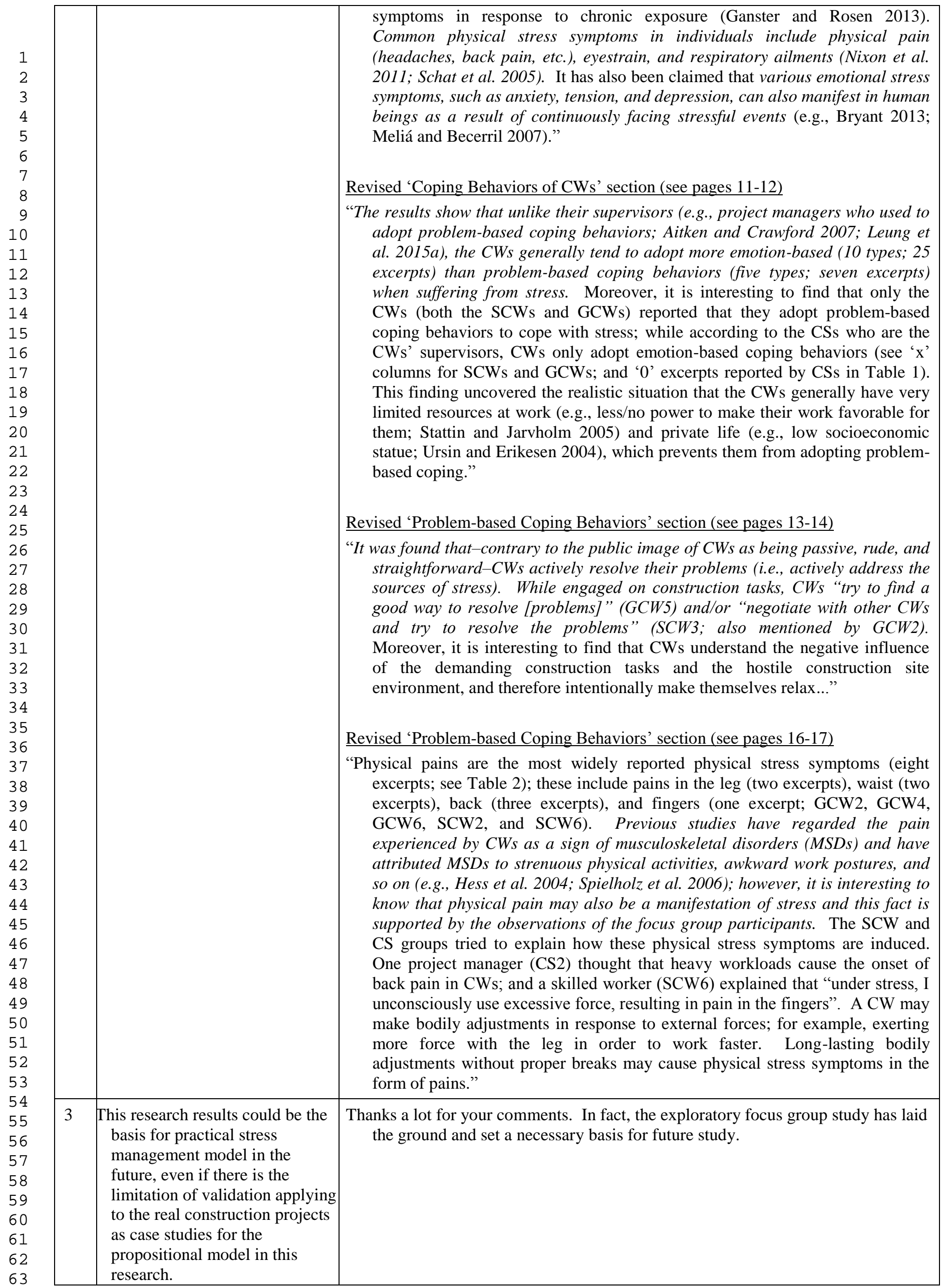


We believe that the above response is sufficient at present and all of editor's comments have been responded. Please don't hesitate to contact me at any time should you have any queries. I look forward to receiving your positive response at your earliest convenience.

Yours faithfully,

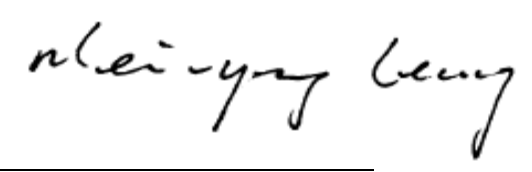

Mei-yung Leung

Encl. - A paper entitled "A Focus Group Study to Explore Critical Factors for Managing Stress of the Construction Workers". 